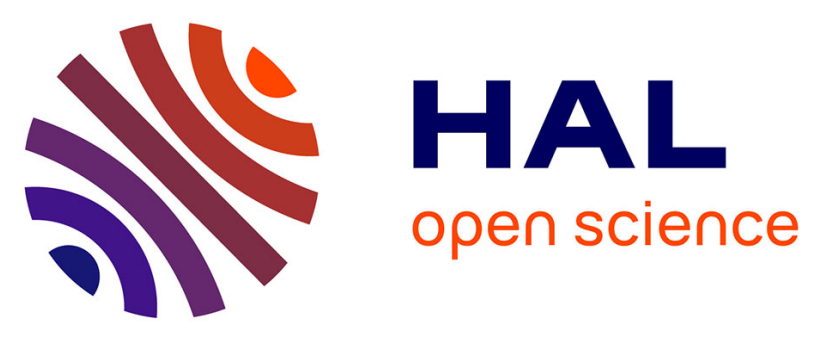

\title{
Layered double hydroxide-indomethacin hybrid: A promising biocompatible compound for the treatment of neuroinflammatory diseases
}

Carla Carolina Ferreira Meneses, Paulo Robson Monteiro de Sousa, Laine

Celestino Pinto, Gerson Maciel Coelho, Tamires Ferreira da Silva, Luan

Oliveira Ferreira, Kayo Silva Gustavo, Arnaldo Jorge Martins-Filho, Kelson

Do Carmo Freitas Faial, Elizabeth Sumi Yamada, et al.

\section{- To cite this version:}

Carla Carolina Ferreira Meneses, Paulo Robson Monteiro de Sousa, Laine Celestino Pinto, Gerson Maciel Coelho, Tamires Ferreira da Silva, et al.. Layered double hydroxide-indomethacin hybrid: A promising biocompatible compound for the treatment of neuroinflammatory diseases. Journal of Drug Delivery Science and Technology, 2021, 61, pp.102190. 10.1016/j.jddst.2020.102190 . hal-03281808

\section{HAL Id: hal-03281808 \\ https: / hal-unilim.archives-ouvertes.fr/hal-03281808}

Submitted on 26 Nov 2021

HAL is a multi-disciplinary open access archive for the deposit and dissemination of scientific research documents, whether they are published or not. The documents may come from teaching and research institutions in France or abroad, or from public or private research centers.
L'archive ouverte pluridisciplinaire $\mathbf{H A L}$, est destinée au dépôt et à la diffusion de documents scientifiques de niveau recherche, publiés ou non, émanant des établissements d'enseignement et de recherche français ou étrangers, des laboratoires publics ou privés. 


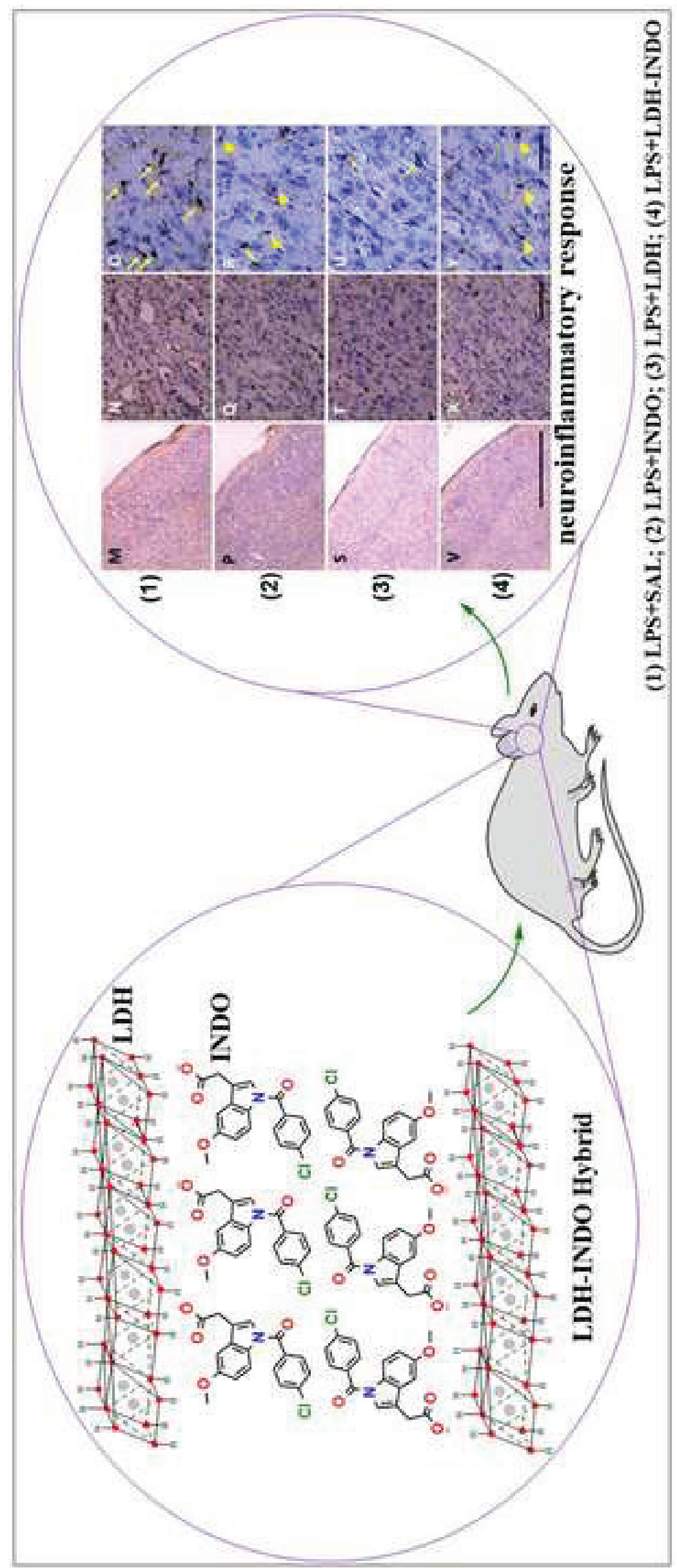




\section{Layered double hydroxide-Indomethacin hybrid: A promising biocompatible compound for treatment of neuroinflammatory diseases}

Authors:

Carla Carolina Ferreira Meneses ${ }^{\mathrm{a}}$, Paulo Robson Monteiro de Sousa ${ }^{\mathrm{a}}$, Laine Celestino Pinto $^{\mathrm{b}}$, Gerson Maciel Coelho ${ }^{\mathrm{b}}$, Tamires Ferreira da Silva ${ }^{\mathrm{b}}$, Luan Oliveira Ferreira ${ }^{\mathrm{b}}$, Kayo Silva Gustavo $^{\mathrm{b}}$, Arnaldo Jorge Martins-Filho ${ }^{\mathrm{c}}$, Kelson do Carmo Freitas Faial ${ }^{\mathrm{c}}$, Elizabeth Sumi Yamada ${ }^{b}$, Jerônimo Lameira ${ }^{\mathrm{a}}$, Jenny Jouin ${ }^{\mathrm{d}}$, Philippe Thomas ${ }^{\mathrm{d}}$, Olivier Masson ${ }^{\mathrm{d}}$, Dielly Catrina Favacho Lopes ${ }^{b^{*}}$, Cláudio Nahum Alves ${ }^{\mathrm{a} *}$

Affiliations:

anstitute of Exact and Natural Sciences, Federal University of Pará, Belém, Pará 66075110, Brazil

bInstitute of Biological Sciences, Federal University of Pará, Belém, Pará 66075-110, Brazil

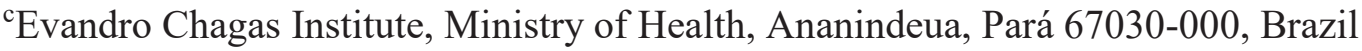

${ }^{\mathrm{d}}$ Laboratoire IRCER, Université de Limoges-CNRS UMR 7315, Centre Européen de la Céramique, Limoges, France

*To whom correspondence should be addressed:

Dr. Cláudio Nahum Alves, Chem. D, PhD

Professor

Institute of Exact and Natural Sciences, Federal University of Pará, Belém, Pará 66075110, Brazil

Tel +55 91-983010969

Fax +55 91- 31831365

Email: nahum@ufpa.br

Dra. Dielly Catrina Favacho Lopes, Farm. D, PhD

Professor

Institute of Biological Sciences, Federal University of Pará, Belém, Pará 66075-110, Brazil Tel +55 91-992993169

Fax +55 91- 31831365

Email: dicatrina@gmail.com 


\title{
Layered double hydroxide-Indomethacin hybrid: A promising biocompatible compound for treatment of neuroinflammatory diseases
}

\begin{abstract}
Indomethacin (INDO) demonstrates therapeutic efficacy in the treatment of neuroinflammatory diseases, but its use causes adverse reactions in the central nervous system (CNS) and gastrointestinal problems. In this study, we investigated nanoparticles of layered double hydroxide (LDH) loaded with INDO. The structure of the nanohybrid (LDH-INDO) was synthesized via a coprecipitation method. The characterization was performed by X-ray powder diffraction (XRD), Infrared spectroscopy (IR), Thermogravimetric (TG-DSC), Field-Emission Scanning Electron Microscopes (FE-SEM) and UV-Vis techniques. Moreover, the drug release profiles from nanohybrid was investigated through kinetics models. The INDO was incorporated within the LDH interlayer space with $50 \%$ of the intercalated compound. The release of indomethacin anion from $\mathrm{LDH}-\mathrm{INDO}$ is $92 \%$ at $\mathrm{pH} 4.8 \pm 0.02$ after 10 hours and $53 \%$ at $\mathrm{pH} 7.4 \pm 0.02$ after 10 hours with an pseudo-second order model in the release profiles. Lipopolysaccharide (LPS)-induced a sickness behavior in animals, and treatment with INDO and LDH-INDO suggests recovery of the variables (weight and intake food). Moreover, LPS increased Iba $1^{+}$cells (microgliosis) and caused morphological alterations of these cells both in the hippocampus and in the somatosensory cortex. However, LPS effect were attenuated after treatment with INDO, both free and LDH-intercalated, in both regions of the brain.
\end{abstract}

Keywords: Layered double hydroxide, Indomethacin, Nanohybrid, Neuroinflammation 


\section{Introduction}

Neuroinflammation is a healthful immune response, however, if excessive, it becomes harmful and, when in a chronic state, it seems to play an important role in the onset and/or progression of neurodegenerative diseases, such as Alzheimer's disease, Parkinson's disease and multiple sclerosis (Kempuraj et al., 2016; Réus et al., 2015) . Some studies support that anti-inflammatory drugs may be beneficial if used at the beginning of these diseases, but on the other hand, it may be harmful if given in the late stages (Bernardi et al., 2012). In view of the neuroinflammatory scenario of neurodegenerative diseases and other neurological disorders, anti-inflammatory drugs have been proposed as auxiliary drug capable of delaying and/or ameliorating these processes (Hamasaki et al., 2018).

Non-steroidal anti-inflammatory drugs (NSAIDs) are a class of aromatic organic compounds with ionizable carboxylic groups. NSAIDs usually show antipyretic, analgesic, and anti-inflammatory activities (Wojek, 2018). They constitute a rather heterogeneous group of drugs which share the ability to inhibit cyclooxygenase (COX) isoforms 1 and 2 activity. COX is an enzyme essential for the synthesis of prostaglandins (PGs), which have a strong propensity for inducing inflammation (Kata et al., 2017; Tomisato et al., 2004). Based on this, these compounds are commonly used in the broad range of diseases associated with inflammatory processes (Wongrakpanich et al., 2018).

Indomethacin (INDO), 1-(4-chlorobenzoyl)-5-methoxy-2-methyl-1H-indole-3acetic acid, which belongs to the NSAIDs class, is a potent inhibitor of both COX-1 and COX-2 (Lucas, 2016). It has been introduced to treat rheumatic inflammatory diseases because of its extensive anti-inflammatory efficacy (Banks et al., 2015) and is also used in many studies as an auxiliary for the treatment of some diseases that affect the CNS, such 
as Alzheimer's disease and multiple sclerosis (Bernardi et al., 2010; Preisner et al., 2015). However, most of the NSAID compounds exhibit adverse effects, especially gastrointestinal, cardiac, cerebrovascular and renal problems (Hopper, 2011; Vostinaru, 2017)

In recent decades, several studies have reported that drug intercalation into layered double hydroxides (LDHs), also known as anionic clays or hydrotalcite like materials reduces adverse effects, such as stomach irritation, and increase the drug solubility (Ambrogi et al., 2003; Gaskell et al., 2018; Rives et al., 2013). The LDHs have the advantages of the easy of preparation, low cost, good biocompatibility, low cytotoxicity, and full protection of the loaded drug (Hesse et al., 2013; Silva et al., 2019). Moreover, it provide the controlled release these drugs (Gaskell et al., 2018; Hashim et al., 2019).

Interestingly, Del Arco et al showed that intercalation of the INDO in the LDH host reduced the ulcerating damage of this drug (Del Arco et al., 2004). Thus, proving that the LDHs are good matrices for formulations intended for application pharmacological of the NSAIDs drugs. In this work, the indomethacin anion (negatively charged, INDO-) was intercalated by coprecipitation method into a biocompatible layered double hydroxide $\left(\mathrm{LDH}, \mathrm{MgAl}-\mathrm{NO}_{3}\right)$. In addition, was investigated the effect by which the INDO anion $\left(\mathrm{INDO}^{-}\right)$released from INDO/MgAl-NO$-\mathrm{MDH}$ hybrid (LDH-INDO) act as in a Lipopolysaccharide (LPS)-induced neuroinflammation model as a potential candidate to assist in the treatment of inflammatory neurological diseases.

\section{Material and methods}

\subsection{Chemicals and reagents}


The indomethacin $\left(\mathrm{C}_{19} \mathrm{H}_{16} \mathrm{ClNO}_{4}\right.$, with a purity of $\left.99 \%\right), \mathrm{Mg}\left(\mathrm{NO}_{3}\right)_{2} \cdot 6 \mathrm{H}_{2} \mathrm{O}$ (SigmaAldrich, 98\%), $\mathrm{Al}\left(\mathrm{NO}_{3}\right)_{3} .9 \mathrm{H}_{2} \mathrm{O}$ (Sigma-Aldrich, 98\%), $\mathrm{NaOH}$ (Sigma-Aldrich, 98\%), Lipopolysaccharide (LPS) derived from Escherichia coli O111:B4 (Sigma-Aldrich Brazil), anti-Iba1 (Sigma-Aldrich Brazil), horse serum (Sigma-Aldrich Brazil), DAB (3,3'diaminobenzidine) chromogen solution (Sigma-Aldrich Brazil) and $\mathrm{CH}_{3} \mathrm{CH}_{2} \mathrm{OH}$ (Alfa Aesar, 94-96\%) were purchased from Sigma-Aldrich Brazil Ltds. The streptavidin-HRP (LSAB2 System-HRP) was purchased from Dako North America Inc. (Carpinteria, CA, USA). All were of analytical grade. The water used was purified with an ELGA Purelab Option labwater.

\subsection{Synthesis}

The LDH $\left(\mathrm{Mg} / \mathrm{Al}^{-\mathrm{NO}_{3}^{-}}\right)^{2}$ were synthesized by a standard coprecipitation method similar to those proposed by Del Arco al. (2004), for comparison purposes, under the same conditions as of the nanohybrid (LDH-INDO) sample (Del Arco et al., 2004). For indomethacin intercalated within the LDH interlayer space, LDH-INDO complex, a mixed aqueous solution containing $\mathrm{Mg}\left(\mathrm{NO}_{3}\right)_{2} \cdot 6 \mathrm{H}_{2} \mathrm{O}$ and $\mathrm{Al}\left(\mathrm{NO}_{3}\right)_{3} \cdot 9 \mathrm{H}_{2} \mathrm{O}$ salts was slowly added to $45 \mathrm{ml}$ of ethanol-water solution $50 \%(\mathrm{v} / \mathrm{v})$ with indomethacin $(1.67 \mathrm{~g})$, the solution $\mathrm{pH}$ was previously adjusted to 8 with dropwise addition of $2 \mathrm{M} \mathrm{NaOH}$ solution. A gel was formed and aged with vigorous stirring at $80{ }^{\circ} \mathrm{C}$ for 24 hours under $\mathrm{N}_{2}$ gas flow to avoid carbonate contamination. The solid was then isolated by centrifugation (1000 rpm for 5 minutes), filtrated and washed with portions of deionized water and ethanol solution (volume ratio 1:1), and finally dried in a vacuum desiccator for 24 hours. 


\subsection{Physical characterization of the LDH-INDO sample}

In this work, different instrumental techniques were used in characterization of the synthesized samples, i.e. powder X-ray diffraction (XRD), Infrared spectroscopy (IR), Raman spectroscopy, Thermogravimetric analyses (TGA-DSC) and Scanning electron microscopy (SEM). The XRD patterns of the powders were recorded with $\mathrm{CuK}_{\alpha 1}$ radiation in the $2 \theta$ range $20-80^{\circ}$ on a $\theta / 2 \theta$ D 8 advance diffractometer (Bruker, Germany) with a step of $0.04^{\circ}$ and exposure time of 2.8 seconds per step. The analysis of the samples were carried out with the Peakoc program (Masson, 2010) using the split pseudo-Voigt function (Thompson, P.; Cox, D. E.; Hastings, 1987) to fit the experimental profiles. The IR spectra were recorded on a Thermo Fisher Nicolet 6700 model spectrometer in air at room temperature (400-4000 $\left.\mathrm{cm}^{-1}\right)$ using the $\mathrm{KBr}$ pellet technique. The Raman spectroscopic analyses were performed on a T64000 Raman spectrometer at the wavelength of 514,532 nm. The TGA-DSC was measured on Netzsch instrument model STA 449F3 (Germany). The thermal analyses were carried out in flowing $(20 \mathrm{ml} / \mathrm{min})$ argon gas, from $25{ }^{\circ} \mathrm{C}$ to $1000{ }^{\circ} \mathrm{C}$ at a heating rate of $10{ }^{\circ} \mathrm{C} / \mathrm{min}$ and morphology of the samples was observed through of the Field-Emission Scanning Electron Microscopes (FE-SEM) with a JEOLJEM-6700 at $5.0 \mathrm{kV}$. The Mg and Al metals was quantified on a Varian ICP optical emission spectrometer (OES), as described in the literature (Sousa et al., 2019). $1 \mathrm{mg}$ of both pristine $\mathrm{LDH}$ and $\mathrm{LDH}^{-}$INDO samples were dissolved in an aqua regia solution. The aliquots were left to cool after which $1 \mathrm{~mL}$ of aliquot was diluted with $9 \mathrm{~mL}$ of deionized water, then measured three times and the average ICP value was recorded.

\subsection{Drug-loading capacity}


The indomethacin (INDO) quantification into LDH $\left(\mathrm{MgAl}-\mathrm{NO}_{3}\right)$ was determined by ultraviolet-visible absorbance (UV-Vis) using Shimadzu UV-2600 model, as described in our previous work (Sousa et al., 2017). Initially, $0.5 \mathrm{ml}$ of ethanol and $0.5 \mathrm{ml}$ of $0.1 \mathrm{M}$ $\mathrm{HCl}$ solution were used to dissolve a milligram of the LDH-INDO complex then diluted with phosphate buffer solution (PBS) at $\mathrm{pH} 7.4 \pm 0.02$ in a $10 \mathrm{ml}$ volumetric flask. The amount of INDO in this solution was determined by measuring the absorbance at $\lambda_{\max }=$ $320 \mathrm{~nm}$, using a calibration curve previously obtained from a series of standard solutions of indomethacin. Furthermore, the solid state UV-Vis spectra for indomethacin and LDHINDO powder were obtained in a range from $200 \mathrm{~nm}$ to $800 \mathrm{~nm}$ with $\mathrm{BaSO}_{4}$ background by using a UV-Vis spectroscope (Shimadzu UV-2600 model).

\subsection{Drug release kinetics}

The in vitro release of INDO was performed following the method described by Sousa et al. (2017) $10 \mathrm{mg}$ of the LDH-INDO was immersed in $100 \mathrm{ml}$ of a phosphate buffer solution (PBS) at $\mathrm{pH} 4.8 \pm 0.02$ and $7.4 \pm 0.02$ with mild shaking at $150 \mathrm{rpm}$ and temperature maintained at $37 \pm 0.5^{\circ} \mathrm{C}$. An aliquot of $5 \mathrm{ml}$ was taken from the suspension and immediately replaced by an equal volume of PBS at $37 \pm 0.5^{\circ} \mathrm{C}$ to keep the temperature and volume constant. The content of INDO in each aliquot was filtered and measured at an absorbance of $320 \mathrm{~nm}$ using a UV/Vis spectrophotometer (Shimadzu UV-2600 model) according to a previously determined calibration curve $\left(y=0,0351 \mathrm{x}-0,0353 ; \mathrm{r}^{2}=0,9997\right)$.

The released percentage at each time point $(1,5,10,15,20,25,30,45,60,75,90$, $120,150,180,240,300,360,420,480,540$ and $600 \mathrm{~min})$ was expressed as a fraction of the total amount of indomethacin anion (INDO-), obtained by an average of the three 
determinations . Finally, the release behavior of the indomethacin from the LDH-INDO was modeled applied three types of dissolution-diffusion kinetic models, a pseudo-second order model (Equation 1), the (Equation 2) (Sakore and Chakraborty, 2013) KorsmeyerPeppas model and the Higuchi model (Equation 3) (Sakore and Chakraborty, 2013).

$$
\begin{gathered}
\frac{t}{q_{t}}=\frac{1}{k q_{e}^{2}}+\frac{t}{q_{e}} \\
\frac{q_{t}}{q_{\infty}}=k t^{n} \\
q_{t}=k \sqrt{t}
\end{gathered}
$$

Where $q_{e}$ and $q_{t}$ are the equilibrium release amounts and the release amounts at any time $(t)$, respectively.

\subsection{Biological assays}

Adults male Wistar rats aged 8 weeks, weighing 200-220 g were assessed in study, all from Instituto Evandro Chagas. All procedures in accordance with National Council for Animal Experimentation Control (CONCEA) and approved by the Ethics Committee in the Use of Animals (Protocol: 1624210617) of the Federal University of Pará. Animals were kept in a temperature-regulated room $\left(22-24^{\circ} \mathrm{C}\right)$ at $12 / 12$ hours light/dark cycle, with water and food ad libitum. The weight body and intake of food were daily measured and calculated as follows:

$$
\Delta \mathrm{BWV}=\mathrm{WD}-\mathrm{FW}
$$

Where $\triangle \mathrm{BWV}, \mathrm{WD}, \mathrm{FW}$ are body weight variation, weight of the day, first weight measured on the day before LPS dose or saline, respectively.

$$
\Delta \mathrm{FIV}=\mathrm{FWD}-\mathrm{FWPD}(5)
$$


Where $\triangle$ FIV, FWD, FWPD are food intake variation, feed weight in the day, feed weight of the previous day, respectively.

The animals received intraperitoneal (i.p.) injections of LPS $(0.75 \mathrm{mg} / \mathrm{kg})$ derived from Escherichia coli O111:B4 dissolved in 0.9\% saline solution or 0.9\% saline solution only (control group) every day for five days in the period from 7:00 to 8:30 a.m. (day 0 to day 4). Pharmacological treatments (LDH, INDO and combinations) were performed 24 hours after the first injection of LPS (day 1) and 48 hours after first doses of the treatments (day 3 ) in the period from 13:00 to 14:30.

The choice of these days was based on the hypothesis that the LDH formulation would provide drug release-sustained, with full release within 48 hours (Gaskell et al., 2018; Gunawan and Xu, 2008; Rives et al., 2014). The dose of INDO was chosen according to previous studies (Boehme et al., 2014; Chao et al., 2012). The drug was dissolved in $0.9 \%$ saline solution with $7 \%$ sodium bicarbonate and given for gavage (Banks et al., 2015).

The concentrations tested for pristine LDH and those for LDH containing indomethacin were based on the INDO intercalation efficiency in the nanoparticle, keeping the indomethacin concentration comparable to those used in the experiments with the drug non-intercalated (free drug). The rats were divided into 8 experimental groups, according to table 2

\subsubsection{Immunohistochemistry}

After euthanasia, brains were removed and fixed in paraformaldehyde (4\%), 30\% sucrose-embedded, and sectioned at $40 \mu \mathrm{m}$. Sections of brain tissues were washed with 
PBS pH $7.4 \pm 0.02$ and incubated with mouse anti-Iba1 (1:1000), diluted in PBS and 3\% horse serum overnight $\left(4^{\circ} \mathrm{C}\right)$. Sections were rinsed in PBS and exposed to sequential incubations of biotinylated link (goat anti-mouse secondary antibody) and streptavidinHRP according to manufacturer's instructions. Binding sites were revealed with DAB chromogen solution and $0.5 \mathrm{M}$ nickel plus hydrogen peroxide. The slices, thus processed, were stained with cresyl violet for 10 minutes. The slides were observed in optical microscope Nikon Labophot 2 (Nikon Instruments Inc., NY, USA) and the images were captured by the digital camera and analyzed using the software Stereologer ${ }^{\mathrm{TM}} 3.0$ software $^{2}$ (Systems Planning \& Analysis, Inc., Alexandria, VA).

\subsubsection{Statistical analysis}

All analyzes were performed in the program GraphPad Prism 8.0 software (San Diego, California, USA). Comparisons of animal weight and food intake were assessed by two-way analysis of variance (ANOVA) (Salkind, 2010) followed by Tukey post-test for multiple comparisons. The data were expressed as mean \pm standard deviation. In all statistics, values were adopted for $\mathrm{p}<0.05$ as statistically significant.

\section{Results}

\subsection{X-ray powder diffraction (XRD)}

The XRD patterns for LDH, before and after intercalation, are shown in Figure 1. They exhibit a series of Bragg reflections peaks, all associated to single phase and wellcrystallized structures typical of hydrotalcite-like materials (Miyata, 1980; Ambrogi et al., 2001; Kastner et al., 2014). The basal spacing of pure LDH (Figure 1A) is about $8.87 \AA$, 
which corresponds to typical values found with intercalated nitrate ions (Dupin et al., 2004). The FWHM (full width at half-maximum) value for LDH is about $0.542^{\circ}$ for the (003) reflection which gives an estimated crystallite coherent size of $138.8 \AA$ along the $c$ direction by the Scherrer equation (Hu and O'Hare, 2005), indicating a stacking of 22-23 monolayers.

The XRD pattern for hybrid solid (LDH-INDO, shown in Figure 1 B) also exhibit sharp and symmetric Bragg reflections of (003), (006) and (009) planes, but they occur at lower angles and exhibit a larger FWHM. This indicates the formation of LDH-INDO intercalation compound, such as described in the literature (Del Arco et al., 2004; L. Mohanambe and Vasudevan, 2005).

In this work, as expected, after the intercalation of INDO the calculated basal spacing corresponding to diffraction by planes $(00 \ell)$ was much larger than for the LDH, because of the dimensions of the drug molecules (width $=7.5 \AA$; length $=14.2 \AA$ ) (Del Arco et al., 2004). This is reflected by the $d$-spacing values expanding from $8.87 \AA$ to 25.29 $\AA$, calculated from the average values of the first, second and third order peaks of the XRD patterns. This is equivalent to a gallery height of $20.41 \AA$ (from the width of the brucitelike layers, $4.8 \AA$ (Drezdzon, 1988), suggesting an arrangement of the drug in the interlayer region in bilayers with the minimal dimension of each anion perpendicular to the brucitelike layers, as stated in the literature (Del Arco et al., 2004; L. Mohanambe and Vasudevan, 2005). This confirms that the drug has indeed been intercalated. This process occurs due to the negative charge of the guest anionic INDO, which is intercalated by the electrostatic force of attraction between the anionic INDO and LDH basal layer (Figure 1). 
Moreover, the estimated coherent size of the crystallites increased to $170.6 \AA$, as calculated from the broadening of the peaks. Finally, no great change is observed in the value of the unit cell parameter $a$ for LDH (4.57 $\AA$ ) and LDH-INDO (4.55 $\AA$ ), calculated from the position of the (110) reflection, which appears at the same position $\left(\sim 60.5^{\circ} 2 \theta\right)$. This indicates that intercalation of the INDO has not changed the structure of the layers but only the interlayer spacing.

\subsection{Infrared spectroscopy (IR) analysis}

The measured FTIR spectra of raw and intercalated LDH (LDH-INDO), shown in Figure 2, are in agreement with the previous observations found in literature, such as bands related to the nitrate, a sharp peak at $1385 \mathrm{~cm}^{-1}$ and a weak peak at $825 \mathrm{~cm}^{-1}$, which confirms that sample is a pristine LDH. Another important support for pristine LDH is the $\mathrm{v}(\mathrm{O}-\mathrm{H})$ stretching vibration at around $3554 \mathrm{~cm}^{-1}$, as well as a peak at $1629 \mathrm{~cm}^{-1}$ characteristic of the $\delta\left(\mathrm{H}_{2} \mathrm{O}\right)$ vibrational model attributed to water molecules between layered of the LDH (MgAl-NO ${ }_{3}$ (Andrade et al., 2000; Kannan et al., 1995). In addition, lattice vibrations of metal-oxygen $\mathrm{v}(\mathrm{M}-\mathrm{O})$ bonds are also observed between $445 \mathrm{~cm}^{-1}$ and $676 \mathrm{~cm}^{-1}$ (Kannan et al., 1995).

For pure indomethacin, the infrared spectra show a sharp band at $1717 \mathrm{~cm}^{-1}$ attributed to the $\mathrm{v}(\mathrm{C}=\mathrm{O})$ stretching of the carboxylic acid, in addition with one from the carbonyl stretch of the non-protonated amide at $1692 \mathrm{~cm}^{-1}$. However, this vibration changes after the intercalation in the LDH gallery to asymmetric carboxylate stretch $v_{\text {as }}\left(\mathrm{COO}^{-}\right)$in the range $1550-1560 \mathrm{~cm}^{-1}$, while symmetric stretch $\mathrm{V}_{\mathrm{as}}\left(\mathrm{COO}^{-}\right)$was recorded between $1480-1300 \mathrm{~cm}^{-1}$, thus confirming that the species intercalated into the LDH layers is the 
anionic form of indomethacin (Del Arco et al., 2004; Mendieta et al., 2012; L. Mohanambe and Vasudevan, 2005). Moreover, other vibrations were detected, for example: $\mathrm{CH}_{3}$ at $2965 \mathrm{~cm}^{-1}$ (asymmetric stretch), $\mathrm{CH}_{3}$ at $2926 \mathrm{~cm}^{-1}$ (symmetric stretch), $\mathrm{C}=\mathrm{O}$ at $1676 \mathrm{~cm}^{-1}$ (benzoyl), $\mathrm{C}=\mathrm{C}$ at 1598 and $1480 \mathrm{~cm}^{-1}$ (aromatic rings), $\mathrm{C}-\mathrm{Cl}$ in range 1061 at $1068 \mathrm{~cm}^{-1}$ and $754 \mathrm{~cm}^{-1}$ (Indole ring vibrations) (Del Arco et al., 2004; L Mohanambe and Vasudevan, 2005; Zhang et al., 2012).

\subsection{Thermogravimetric analysis (TG-DSC)}

Weight loss as a function of temperature for LDH, pure INDO and LDH-INDO were obtained using TG-DSC curves (Figure 3). Three weight-loss steps are observed for $\mathrm{LDH}\left(\mathrm{MgAl}-\mathrm{NO}_{3}\right)$, the first one is related to the removal of interlayer water molecules, with an endothermic peak at $160{ }^{\circ} \mathrm{C}$ in DSC curve, the second one being due to the dehydroxylation of the inorganic layers and decomposition of intercalated nitrate anions in the temperature range of 300 to $600{ }^{\circ} \mathrm{C}$ (Whilton et al., 1997). Finally, the total degradation occurs at $900^{\circ} \mathrm{C}$ (Figure 3). Pure indomethacin exhibits a single-stage thermal degradation, with endothermic a peak at $56{ }^{\circ} \mathrm{C}$ attributed to the melting of the drug (Figure 3). The complete thermal decomposition occurs at $300{ }^{\circ} \mathrm{C}$ due to the exothermic effect of decomposition phenomena in its DSC curve (Ambrogi et al., 2003).

TG-DSC curves for the LDH-INDO shows a first weight loss at $100{ }^{\circ} \mathrm{C}$, corresponding to the removal of interlayer water molecules (Figure 3). A second weight loss in the range 200 to $450{ }^{\circ} \mathrm{C}$ characterized by the presence of a small exothermic peak at $350^{\circ} \mathrm{C}$ could be ascribed to drug degradation, releasing probably $\mathrm{CO}_{2}, \mathrm{NO}_{2}$ and $\mathrm{H}_{2} \mathrm{O}$. A third step from 500 to $600{ }^{\circ} \mathrm{C}$, with the presence of an intense exothermic peak at $550{ }^{\circ} \mathrm{C}$ 
in DSC, was also due to the partial decomposition of intercalated INDO anions and dehydroxylation of the LDH layers (Del Arco et al., 2004). This process ended at $900{ }^{\circ} \mathrm{C}$, corresponding to the total removal of hydroxyl groups from the layers. Therefore, these results indicate that the chemical stability of the drug is increased after the intercalation process. Furthermore, data obtained through the ICP allowed calculating the chemical composition of the samples, as shown in Table 1, and are consistent with those found in the literature (Del Arco et al., 2004).

\subsection{Surface morphology studies}

The morphology observed in pure LDH and LDH-INDO are similar to what was previously seen in Magnesium and aluminum based LDH clays, usually platelets-like morphology, as shown in Figure 4 (Sousa et al., 2017; Tao et al., 2006). The FE-SEM images of LDH suggest a particle size of about 100 at $160 \mathrm{~nm}$ and a thickness of a few nanometers (Figure 4A). This thickness indicates that the particles are composed of a small number of layers (typically less than 10). As expected, the intercalation of INDO anions strongly influenced the morphology properties of LDH (Ambrogi et al., 2003), and consequently gave rise to an irregular structure with aggregated particles. It may be due to the adsorption of INDO anions on positively charged LDH surface, which hiders the full growth of the particles (Figure 4B) (Zhang et al., 2014). Moreover, these results confirmed the conclusions from XRD and IR, and indicated the formation LDH-INDO.

\subsection{Quantification and release study of LDH-INDO complex}


The amount of indomethacin intercalated into LDH gallery was calculated at 50\% (w/w) a good result when compared to the $48 \%$ obtained by Mendieta et al. (2012) and $36 \%$ presented in the work of the Del arco et al. (2004), both for indomethacin intercalated into MgAl-LDH by coprecipitation method. The UV-Vis specters of both pure INDO and INDO released from the LDH-INDO are show in the Figure 5. These data were obtained using a PBS at pH $7.4 \pm 0.02$ as well as in the solid state. In solution, three absorbance peaks are visible at $211 \mathrm{~nm}, 270 \mathrm{~nm}$ and $320 \mathrm{~nm}$, which is in good agreement with the literature data (Sugandha Singh, Rajesh Kumar Maheshwari, 2018). In addition, the UVVis solid state spectrum (Figure 5) confirmed the effective intercalation of the indomethacin in the LDH through of the increase in intensity and absorption in the UV and in the visible regions.

In this analysis it is clear that LDH-INDO possessed higher UV absorption capacity as compared with pure indomethacin, thus, suggesting that the indomethacin was intercalated into LDH gallery instead of degraded in the synthesis process. Finally, the release profiles of indomethacin anion from its LDH-INDO performed in a PBS at pH 4.8 \pm 0.02 and $\mathrm{pH} 7.4 \pm 0.02$ are shown in the Figure 6 . The curves obtained indicate that in this $\mathrm{pH}$ range, release of indomethacin from $\mathrm{LDH}-\mathrm{INDO}$ is approximately of $90 \%$ and $51 \%$ after 10 hours when exposed to $\mathrm{pH} 4.8 \pm 0.02$ and $7.4 \pm 0.02$, respectively.

According to the literature, $\mathrm{LDH}-\mathrm{drug}$ hybrids materials can exhibit a release at $\mathrm{pH}$ $4.8 \pm 0.02$ and $7.4 \pm 0.02$ following different molecular mechanisms (Ambrogi et al., 2008; Lima et al., 2013). A greater stability was demonstrated at pH $7.4 \pm 0.02$ instead of $4.8 \pm$ 0.02 due to electrostatic interactions between the organic anions and the positively charged LDH layers (Tyner et al., 2004). The release at $\mathrm{pH} 7.4 \pm 0.02$ indeed occurs via an ion 
exchange with the ions in the buffer solution, while the release at $\mathrm{pH} 4.8 \pm 0.02$ occurs through both dissolution of the LDH layers and ion exchange (Kura et al., 2013; Tyner et al., 2004). From this information, the pseudo-second order equation (El Zowalaty et al., 2014; Ho and Ofomaja, 2006), Korsmeyer-Peppas and Higuchi models (Sakore and Chakraborty, 2013) were used as fitting standard release to the experimental data. It can be seen that the pseudo-second order model is the better fitted to the data for INDO release behavior than the other models.

The plots of $t / q_{\mathrm{t}}$ versus $t$ (pseudo-second order model) for the release of INDO show that the correlation coefficient $\left(\mathrm{r}^{2}\right)$ value was $>0.99$ which is slightly higher compared to the other models, however, all data is well adjusted (see Table 1). The burst effect observed in the matrix during the first 2 hours could be due to the release of intercalated ions. The slow release from the second to the 10 hours, can be attributed to the release of indomethacin anion from deeper interlayer sites (see Figure 6), where the effective distance to diffuse up to the edges reduces the release rate, together with a possible increase in the rigidity of the layers (Lima et al., 2013; Sousa et al., 2019).

\subsection{Biological assays}

Effects of treatment with LDH-INDO on body weight and food intake in animal model of subacute inflammation induced by LPS. In control groups (animals that received $0.9 \%$ saline solution i.p.), our results showed a similar food intake, with an increase only between SAL+SAL and SAL+INDO in day 4 and an increase body weight variation from day 3, compared to day 0 . Those data confirming that LDH, pure INDO and LDH-INDO did not alter appetite and weight of the animals (Figure 7 and Figure 8). 
On the other hand, LPS groups showed a reduction of food intake from day 1 to day 4 when compared to control groups, being that on the day 3 there were only a reduction when compared SAL + SAL, SAL + LDH and SAL + LDH-INDO with LPS + LDHINDO. Also, there was a decrease when SAL + LDH-INDO group was compared to LPS + SAL and LPS + LDH on the day 3. From day 4, all LPS groups increased food intake when compared to day 1 .

Furthermore, LPS groups exhibited a significant weight loss during the experiment in comparison with control groups $(\mathrm{p}<0.0001)$. However, LPS + LDH-INDO regained weight in day 3 and day 5 when compared with day 0 and day 1, respectively. Whereas LPS + INDO recovered weight only in day 5 in relation to day 1 and day 2 , suggesting that LDH-INDO was able to recover the animals more quickly than pure INDO.

Therefore, these data suggest that LPS induced a sickness behavior in animals, characterized by decreased appetite and weight loss and treatment with pure INDO and LDH-INDO appear recovery the variables worked in this study. Effects of LDH-INDO on the microglial activation in the somatosensory cortex and hippocampus of rats undergoing LPS-induced neuroinflammation.

Microglial activation of somatosensory cortex and hippocampus were performed by immunohistochemistry of anti-Ibal. With regard to the somatosensory cortex, an equivalent number of $\mathrm{Iba}^{+}$cells were observed in all control groups, which expressed prolonged and narrow branches, and a reduced somatic size (Figure 9A-L). In the LPS + SAL (Figure 9M-O) and LPS + LDH (Figure 9S-U) groups there was intense microglial activation in the cerebral parenchyma, with qualitative elevation of number of microglia. These presented a slightly branched phenotype, with thickening of the projections and 
increased somatic size, when visually compared to control groups, respectively, (SAL + SAL and SAL + LDH), suggesting intense microglial activation.

The LPS + INDO (Figures 9P-R) and LPS + LDH-INDO (Figures 9V-Y) exhibited discrete cortical microgliosis. However, these cells presented phenotypic characteristics of a quiescent morphology with reduced cell body and thin projections, although a discrete presence of microglia with activated pattern in the cortex is still visualized, suggesting control of the neuroinflammation induced by LPS.

In relation to the hippocampus, control groups were qualitatively observed a number of $\mathrm{Iba1}^{+}$cells decreased with predominance of quiescent pattern (Figure 10A-L). In LPS + SAL (Figure 10M-O) and LPS + LDH (Figure 10S-U) groups there were progressive microglial activation (microgliosis), with apparent increase in the number of Iba $1^{+}$cells, presenting a phenotypic morphology of activation stage, marked by increase in the somatic body, compared to the SAL + SAL, and decrease in thickening of projections.

LPS + INDO (Figure 10P-R) and LPS + LDH-INDO (Figure 10V-Y) presented microgliosis, characterized by visible increase of positively labeled cells. However, these cells have characteristics of a quiescent morphology, with a decrease in soma size and narrowing of the projections, suggesting control of the inflammatory process induced by LPS.

\section{Discussion}

It has long been argued that inflammation can be controlled and/or reduced with the use of NSAIDs. These drugs are capable of suppressing the inflammatory response triggered by several agents, such as bacteria and endotoxins, as well as attenuating 
neuroinflammation in the model of neurodegenerative diseases (Bastos et al., 2008; Bernardi et al., 2010; Preisner et al., 2015). In the present study, although we demonstrated that INDO groups had shown a faster recovery, the LDH-INDO outcomes was more effectivity and quickly than pure INDO against the inflammatory process induced by LPS. These findings about the INDO free are similar to those found by Banks et al. (2015). where the drug inhibited the increase of BBB permeability to sucrose induced by LPS, which also prevented the loss of body weight induced by this endotoxin, suggesting attenuation of sickness behavior, as also observed in our experiments (Banks et al., 2015).

Recently, it has been reported that peripheral infections accompanied by chronic inflammation represent the main risk factors for the development of neurodegenerative diseases, such as Alzheimer's disease and Parkinson's disease (Holmes, 2013; Su and Federoff, 2014). During an inflammatory response, the activation of microglia leads to the retraction of their processes and swelling of the cell bodies with subsequent loss of brain monitoring. This may induce neuronal damage, rupture of relevant circuits and, in the case of uncontrolled or chronic neuroinflammation, decline sensory-cognitive (Tremblay et al., 2011).

In view of the above, the neuroinflammation induced by LPS in the present study was evidenced by the increase of $\mathrm{Iba1}^{+}$cells (microgliosis) and by the morphological alteration of these cells, characterized by the slightly branched phenotype, with thickening of the projections and increased somatic size (microglial activation), both in the hippocampus and in the somatosensory cortex. Furthermore, we observed that these morphological and functional changes induced by LPS were attenuated after treatment with INDO, both free and LDH-intercalated, in both regions of the brain. 
Differently from that observed by Banks et al. (2015) in which treatment with INDO was not able to attenuate the microglial activation in the cortex of mice twenty-four hours after a single injection of LPS, we qualitatively show that groups treated with INDO, both pure INDO and LDH-INDO, was able to decrease microglial activation.

As INDO acts by non-selectively blocking COX activity by reducing the production of prostaglandins, here we observe a decrease in LPS-induced neuroinflammation through the administration of INDO (pure INDO and LDH-INDO), by decreasing the activation profile of the microglia cells. We suggest that the breakdown of BBB homeostasis caused by LPS occurs via a COX-dependent pathway. In addition, we suggest that INDO may modulate transcription factors in the microglia, inducing these cells to reduce the release of proinflammatory cytokines.

Although INDO and LDH-INDO has shown better effects than free-INDO, we believe that further studies should be conducted with regard to the choice of doses administered, as well as when, in the disease process, different formulations should be introduced to improve the outcomes.

\section{Conclusion}

In this work, INDO anion was intercalated into a LDH by a simple coprecipitation method. This anion incorporated within the LDH interlayer space (LDH-INDO) were analyzed by XRD, FT-IR, TGA-DSC, and UV-vis. The spectroscopic studies (FT-IR and UV-vis solid) confirmed that only the unprotonated form of INDO intercalates within the basal spacing. The structural study of the LDH-INDO complex showed that the intercalation of INDO only affects the interlayer area without major modification in the 
brucite-type layers. Moreover, the results showed an intercalation percentage of $50 \%(\mathrm{w} / \mathrm{w})$ of the INDO anion intercalated within the LDH interlayer space. The in vivo assays performed on male Wistar rats revealed that INDO groups had shown a faster recovery, the LDH-INDO outcomes was more effectivity and quickly than pure INDO against the inflammatory process induced by LPS. Our results also highlight the importance of LDH as optimal way for as a drug carrier.

\section{Acknowledgments}

This work was supported by the Brazilian agencies CAPES, MCTI/CNPq $\left(\mathrm{n}^{\circ}\right.$ 42466220167), FAPESPA and PROPESP/UFPA. The work was also partially supported by the French CAPES-COFECUB program (Ph-C 780-13). The authors would like to thanks $\mathrm{PhD} \mathrm{P}$. Thomas, $\mathrm{PhD} \mathrm{P}$. O. Masson and $\mathrm{PhD}$ J. Jouin, for their valuable contributions in this work. Finally, the authors also acknowledge the use of the facilities at Laboratoire IRCER/Université de Limoges-CNRS, Labnano-Amazon/Federal University of Pará and Toxicology Laboratory/Evandro Chagas Institute.

\section{References}

Ambrogi, V., Fardella, G., Grandolini, G., Nocchetti, M., Perioli, L., 2003. Effect of hydrotalcite-like compounds on the aqueous solubility of some poorly water-soluble drugs. J. Pharm. Sci. 92, 1407-1418. doi:10.1002/jps.10411

Ambrogi, V., Fardella, G., Grandolini, G., Perioli, L., 2001. Intercalation compounds of hydrotalcite-like anionic clays with antiinflammatory agents - I. Intercalation and in vitro release of ibuprofen. Int. J. Pharm. 220, 23-32. doi:10.1016/S0378- 
5173(01)00629-9

Ambrogi, V., Perioli, L., Marmottini, F., Accorsi, O., Pagano, C., Ricci, M., Rossi, C., 2008. Role of mesoporous silicates on carbamazepine dissolution rate enhancement. Microporous Mesoporous Mater. 113, 445-452.

doi:10.1016/j.micromeso.2007.12.003

Andrade, A., Namora, S.., Woisky, R.., Wiezel, G., Najjar, R., Sertié, J.A.., de Oliveira Silva, D., 2000. Synthesis and characterization of a diruthenium-ibuprofenato complex. J. Inorg. Biochem. 81, 23-27. doi:10.1016/S0162-0134(00)00106-9

Banks, W.A., Gray, A.M., Erickson, M.A., Salameh, T.S., Damodarasamy, M., Sheibani, N., Meabon, J.S., Wing, E.E., Morofuji, Y., Cook, D.G., Reed, M.J., 2015. Lipopolysaccharide-induced blood-brain barrier disruption: Roles of cyclooxygenase, oxidative stress, neuroinflammation, and elements of the neurovascular unit. J. Neuroinflammation 12, 223. doi:10.1186/s12974-015-0434-1

Bastos, G.N., Moriya, T., Inui, F., Katura, T., Nakahata, N., 2008. Involvement of cyclooxygenase-2 in lipopolysaccharide-induced impairment of the newborn cell survival in the adult mouse dentate gyrus. Neuroscience $155,454-462$. doi:10.1016/j.neuroscience.2008.06.020

Bernardi, A., Frozza, R.L., Horn, A.P., Campos, M.M., Calixto, J.B., Salbego, C., Pohlmann, A.R., Guterres, S.S., Battastini, A.M.O., 2010. Protective effects of indomethacin-loaded nanocapsules against oxygen-glucose deprivation in organotypic hippocampal slice cultures: Involvement of neuroinflammation. Neurochem. Int. 57, 629-636. doi:10.1016/j.neuint.2010.07.012

Bernardi, A., Frozza, R.L., Meneghetti, A., Hoppe, J.B., Battastini, A.M.O., Pohlmann, 
A.R., Guterres, S.S., Salbego, C.G., 2012. Indomethacin-loaded lipid-core nanocapsules reduce the damage triggered by A $\beta 1-42$ in Alzheimer's disease models. Int. J. Nanomedicine 7, 4927-4942. doi:10.2147/IJN.S35333

Boehme, M., Guenther, M., Stahr, A., Liebmann, M., Jaenisch, N., Witte, O.W., Frahm, C., 2014. Impact of indomethacin on neuroinflammation and hippocampal neurogenesis in aged mice. Neurosci. Lett. 572, 7-12. doi:10.1016/j.neulet.2014.04.043

Chao, P.K., Lu, K.T., Jhu, J.Y., Wo, Y.Y.P., Huang, T.C., Ro, L.S., Yang, Y.L., 2012. Indomethacin protects rats from neuronal damage induced by traumatic brain injury and suppresses hippocampal IL-1 $\beta$ release through the inhibition of Nogo-A expression. J. Neuroinflammation 9. doi:10.1186/1742-2094-9-121

Del Arco, M., Cebadera, E., Gutiérrez, S., Martín, C., Montero, M.J., Rives, V., Rocha, J., Sevilla, M.A., 2004. Mg,Al layered double hydroxides with intercalated indomethacin: Synthesis, characterization, and pharmacological study. J. Pharm. Sci. 93, 1649-1658. doi:10.1002/jps.20054

Drezdzon, M.A., 1988. Synthesis of isopolymetalate-pillared hydrotalcite via organicanion-pillared precursors. Inorg. Chem. 27, 4628-4632. doi:10.1021/ic00298a024 Dupin, J.-C., Martinez, H., Guimon, C., Dumitriu, E., Fechete, I., 2004. Intercalation compounds of $\mathrm{Mg}-\mathrm{Al}$ layered double hydroxides with dichlophenac: different methods of preparation and physico-chemical characterization. Appl. Clay Sci. 27, 95-106. doi:10.1016/j.clay.2004.03.001

El Zowalaty, M., Webster, T.J., Zobir Hussein, M., Ismail, M., Hussein-Al-Ali, S., 2014. Synthesis, characterization, controlled release, and antibacterial studies of a novel 
streptomycin chitosan magnetic nanoantibiotic. Int. J. Nanomedicine 9, 549-557. doi:10.2147/IJN.S53079

Gaskell, E.E., Ha, T., Hamilton, A.R., 2018. Ibuprofen intercalation and release from different layered double hydroxides. Ther. Deliv. 9, 653-666. doi:10.4155/tde-20180046

Graphpad Software, 2018. GraphPad Prism. www.graphpad.com.

Gunawan, P., Xu, R., 2008. Direct Control of Drug Release Behavior from Layered Double Hydroxides through Particle Interactions 97, 4367-4378. doi:10.1002/jps Hamasaki, M.Y., Machado, M.C.C., Pinheiro da Silva, F., 2018. Animal models of neuroinflammation secondary to acute insults originated outside the brain. J. Neurosci. Res. doi:10.1002/jnr.24184

Hashim, N., Sharif, S.N.M., Muda, Z., Md Isa, I., Ali, N.M., Bakar, S.A., Sidik, S.M., Hussein, M.Z., 2019. Preparation of zinc layered hydroxide-ferulate and coated zinc layered hydroxide-ferulate nanocomposites for controlled release of ferulic acid. Mater. Res. Innov. 23, 233-245. doi:10.1080/14328917.2018.1444696

Hesse, D., Badar, M., Glage, S., Kieke, M., Behrens, P., Paul, P., Stieve, M., Kristian, N., 2013. Layered double hydroxides as efficient drug delivery system of ciprofloxacin in the middle ear : an animal study in rabbits. J Mater Sci Mater Med 24, 129-136. doi:10.1007/s10856-012-4769-1

Ho, Y., Ofomaja, A.E., 2006. Pseudo-second-order model for lead ion sorption from aqueous solutions onto palm kernel fiber 129, 137-142. doi:10.1016/j.jhazmat.2005.08.020

Holmes, C., 2013. Review: Systemic inflammation and Alzheimer's disease. 
Neuropathol. Appl. Neurobiol. doi:10.1111/j.1365-2990.2012.01307.x

Hopper, I., 2011. Cardiac effects of non-cardiac drugs. Aust. Prescr. 34, 52-54.

doi:10.18773/austprescr.2011.030

Hu, G., O'Hare, D., 2005. Unique layered double hydroxide morphologies using reverse microemulsion synthesis. J. Am. Chem. Soc. 127, 17808-13. doi:10.1021/ja0549392

Kannan, S., Velu, S., Ramkumar, V., Swamy, C.S., 1995. Synthesis and physicochemical properties of cobalt aluminium hydrotalcites. J. Mater. Sci. 30, 1462-1468. doi:10.1007/BF00375249

Kastner, E., Kaur, R., Lowry, D., Moghaddam, B., Wilkinson, A., Perrie, Y., 2014. Highthroughput manufacturing of size-tuned liposomes by a new microfluidics method using enhanced statistical tools for characterization. Int. J. Pharm. 477, 361-368. doi:10.1016/j.ijpharm.2014.10.030

Kata, D., Földesi, I., Feher, L.Z., Hackler, L., Puskas, L.G., Gulya, K., 2017. A novel pleiotropic effect of aspirin: Beneficial regulation of pro- and anti-inflammatory mechanisms in microglial cells. Brain Res. Bull. 132, 61-74.

doi:10.1016/j.brainresbull.2017.05.009

Kempuraj, D., Thangavel, R., Natteru, P.A., Selvakumar, G.P., Saeed, D., Zahoor, H., Zaheer, S., Iyer, S.S., Zaheer, A., 2016. Neuroinflammation Induces Neurodegeneration. J. Neurol. Neurosurg. spine 1.

Kura, A.U., Ali, S.H.H. Al, Hussein, M.Z., Fakurazi, S., Arulselvan, P., 2013. Development of a controlled-release anti-parkinsonian nanodelivery system using levodopa as the active agent. Int. J. Nanomedicine 8, 1103-1110. doi:10.2147/IJN.S39740 
Lima, E., Flores, J., Cruz, A.S., Leyva-Gómez, G., Krötzsch, E., 2013. Controlled release of ferulic acid from a hybrid hydrotalcite and its application as an antioxidant for human fibroblasts. Microporous Mesoporous Mater. 181, 1-7. doi:10.1016/j.micromeso.2013.07.014

Lucas, S., 2016. The Pharmacology of Indomethacin. Headache 56, 436-446. doi:10.1111/head.12769

Masson, 2010. Peakoc Program.

Mendieta, S., Nuñez, P.R., Oliva, M., Pérez, C., Fernández, J., Crivello, M., 2012. Intercalation of Anti-inflammatory Drugs Sodium Indomethacin into Nanocomposites of Mg-Al. Structural Characterization. Procedia Mater. Sci. 1, 580 587. doi:10.1016/j.mspro.2012.06.078

Miyata, S., 1980. Physico-Chemical Properties of Synthetic Hydrotalcites in Relation to Composition. Clays Clay Miner. 28, 50-56. doi:10.1346/CCMN.1980.0280107

Mohanambe, L., Vasudevan, S., 2005. Anionic clays containing anti-inflammatory drug molecules: comparison of molecular dynamics simulation and measurements. J. Phys. Chem. B 109, 15651-8. doi:10.1021/jp050480m

Preisner, A., Albrecht, S., Cui, Q.L., Hucke, S., Ghelman, J., Hartmann, C., Taketo, M.M., Antel, J., Klotz, L., Kuhlmann, T., 2015. Non-steroidal anti-inflammatory drug indometacin enhances endogenous remyelination. Acta Neuropathol. 130, 247261. doi:10.1007/s00401-015-1426-Z

Réus, G.Z., Fries, G.R., Stertz, L., Badawy, M., Passos, I.C., Barichello, T., Kapczinski, F., Quevedo, J., 2015. The role of inflammation and microglial activation in the pathophysiology of psychiatric disorders. Neuroscience. 
doi:10.1016/j.neuroscience.2015.05.018

Rives, V., del Arco, M., Martín, C., 2014. Intercalation of drugs in layered double hydroxides and their controlled release: A review. Appl. Clay Sci. doi:10.1016/j.clay.2013.12.002

Rives, V., Del Arco, M., Martín, C., 2013. Layered double hydroxides as drug carriers and for controlled release of non-steroidal antiinflammatory drugs (NSAIDs): a review. J. Control. Release 169, 28-39. doi:10.1016/j.jconrel.2013.03.034

Sakore, S., Chakraborty, B., 2013. Formulation and evaluation of enalapril maleate sustained release matrix tablets 4, 21-26.

Salkind, N.J., 2010. Encyclopedia of research design dependent variable. Encycl. Res. Des. 1499-1503. doi:10.4135/9781412961288

Silva, T.A. da, Silva, T.A. da, Nascimento, T.G. do, Yatsuzuka, R.E., Grillo, L.A.M., Dornelas, C.B., 2019. Recent advances in layered double hydroxides applied to photoprotection. Einstein (São Paulo) 17, 1-6. doi:10.31744/einstein journal/2019RW4456

Sousa, R., da Silva, B., Dias, A., Meneses, C., Bentes, B., Silva, E., Remédios, C., Feio, W., Masson, O., Alves, C., Arruda, M., Lameira, J., 2019. Ferulate Anion Intercalated into Zn/Al Layered Double Hydroxide: A Promising Intercalation Compound for Inhibition of Leishmania (L.) amazonensis. J. Braz. Chem. Soc. doi:10.21577/0103-5053.20190012

Sousa, R., Jouin, J., Masson, O., Remondiere, F., Lemarchand, A., Colas, M., Thomas, P., Lameira, J., Bastos, G.N.T., Lima, A.B., Nascimento, J.L.M., Anicete-Santos, M., Monteiro, W.R., Alves, C.N., 2017. Structure and analgesic properties of 
layered double hydroxides intercalated with low amounts of ibuprofen. J. Am. Ceram. Soc. 100, 2712-2721. doi:10.1111/jace.14763

Su, X., Federoff, H.J., 2014. Immune responses in parkinson's disease: Interplay between central and peripheral immune systems. Biomed Res. Int. doi:10.1155/2014/275178

Sugandha Singh, Rajesh Kumar Maheshwari, N.G., 2018. Formulation development of topical solutions of poorly water-soluble drug indomethacin employing novel application of mixed solvency concept and their evaluation. Int. J. Green Pharm. 12, $113-120$.

Tao, Q., Zhang, Y., Zhang, X., Yuan, P., He, H., 2006. Synthesis and characterization of layered double hydroxides with a high aspect ratio. J. Solid State Chem. 179, 708715. doi:10.1016/j.jssc.2005.11.023

Thompson, P.; Cox, D. E.; Hastings, J.B., 1987. Rietveld Refinement of Debye-Scherrer Synchrotron X-ray Data from A1203. J. Appl. Crystallogr. 20, 79-83.

Tomisato, W., Tanaka, K.I., Katsu, T., Kakuta, H., Sasaki, K., Tsutsumi, S., Hoshino, T., Aburaya, M., Li, D., Tsuchiya, T., Suzuki, K., Yokomizo, K., Mizushima, T., 2004. Membrane permeabilization by non-steroidal anti-inflammatory drugs. Biochem. Biophys. Res. Commun. 323, 1032-1039. doi:10.1016/j.bbrc.2004.08.205

Tremblay, M.-E., Stevens, B., Sierra, A., Wake, H., Bessis, A., Nimmerjahn, A., 2011. The Role of Microglia in the Healthy Brain. J. Neurosci. 31, 16064-16069. doi:10.1523/jneurosci.4158-11.2011

Tyner, K.M., Schiffman, S.R., Giannelis, E.P., 2004. Nanobiohybrids as delivery vehicles for camptothecin. J. Control. Release 95, 501-514. doi:10.1016/j.jconrel.2003.12.027 
Vostinaru, O., 2017. Adverse Effects and Drug Interactions of the Non- Steroidal AntiInflammatory Drugs, in: Nonsteroidal Anti-Inflammatory Drugs. doi:10.5772/intechopen.68198

Whilton, N.T., Vickers, P.J., Mann, S., 1997. Bioinorganic clays: synthesis and characterization of amino- and polyamino acid intercalated layered double hydroxides. J. Mater. Chem. doi:10.1039/a701237c

Wojek, N., 2018. Non-steroidal anti-inflammatory drugs, in: Drugs in Sport, Seventh Edition. pp. 319-327. doi:10.4324/9781315222790

Wongrakpanich, S., Wongrakpanich, A., Melhado, K., Rangaswami, J., 2018. A Comprehensive Review of Non-Steroidal Anti-Inflammatory Drug Use in The Elderly. Aging Dis. 9, 143. doi:10.14336/ad.2017.0306

Zhang, G.C., Lin, H.L., Lin, S.Y., 2012. Thermal analysis and FTIR spectral curve-fitting investigation of formation mechanism and stability of indomethacin-saccharin cocrystals via solid-state grinding process. J. Pharm. Biomed. Anal. 66, 162-169. doi:10.1016/j.jpba.2012.03.039

Zhang, X., Zeng, M., Li, S., Li, X., 2014. Colloids and Surfaces B : Biointerfaces Methotrexate intercalated layered double hydroxides with different particle sizes : Structural study and Controlled release properties 117, 98-106. 


\section{Table captions}

Table 1. Chemical compositions of the synthesized samples, correlation coefficient $\left(\mathrm{R}^{2}\right)$ obtained by fitting indomethacin release data from LDH-INDO nanohybrid into phosphatebuffered saline at $\mathrm{pH} 7.4$ and $\mathrm{pH} 4.8$, and amount INDO- anions intercalated into LDH.

Table 2 Experimental design.

\section{Figure captions}

Figure 1 XRD patterns of the LDH and nanohybrid (LDH-INDO).

Figure 2 IR spectra of LDH, (B) pure INDO and (C) LDH-INDO complex.

Figure 3 TGA (A) and DSC (B) curves of the LDH, indomethacin pure (B) and nanohybrid (LDH-INDO).

Figure 4 FE-SEM images of LDH and LDH-INDO complex.

Figure 5 Solution UV-Vis spectra of INDO pure (A), released INDO from the LDH-INDO (B). Solid-state UV-Vis spectra of the neutral INDO (C) and LDH-INDO complex (C).

Figure 6 Release profiles for indomethacin from the LDH-INDO complex at $\mathrm{pH} 7.4$ and $\mathrm{pH} 4.8$.

Figure 7 Food intake variation $(\mathrm{g})$ in rats treated by gavage with SAL $(0.9 \%$ saline solution with $7 \%$ sodium bicarbonate), LDH $(10 \mathrm{mg} / \mathrm{kg})$, INDO $(5 \mathrm{mg} / \mathrm{kg})$ and LDH + INDO (10 $\mathrm{mg} / \mathrm{kg}$ ) after intraperitoneal injections of LPS (LPS groups) or $0.9 \%$ saline solution (control groups). The bars represent the mean \pm standard deviation of food consumption measured daily compared to control groups $* p<0.05,{ }^{*} p<0.01, * * * p<0.001, * * * * p<0.0001$ by 2 way in each day; compared to day $0{ }^{\#} \mathrm{p}<0.05,{ }^{\# \#} \mathrm{p}<0.01,{ }^{\# \#} \mathrm{p}<0.001,{ }^{\# \# \#} \mathrm{p}<0.0001$; compared to day $1{ }_{p}<0.05,{ }^{\$}{ }_{p}<0.01,{ }^{\$} \$ p<0.001,{ }^{\$} \$ \$ p<0.0001$; compared to day $2{ }^{\&}<<0.05$, ${ }^{\&} \& \mathrm{p}<0.01,{ }^{\& \& \&} \mathrm{p}<0.001,{ }^{\& \& \& \&} \mathrm{p}<0.0001 ;$ compared to day $3{ }^{\alpha} \mathrm{p}<0.05,{ }^{\alpha \alpha} \mathrm{p}<0.01,{ }^{\alpha \alpha \alpha} \mathrm{p}<0.001$, ${ }_{\alpha \alpha \alpha} \mathrm{p}<0.0001$ between groups by ANOVA followed by Tukey posttest.

Figure 8 Body weight variation $(\mathrm{g})$ in rats treated by gavage with SAL $(0.9 \%$ saline solution with $7 \%$ sodium bicarbonate), LDH (10 mg/kg), INDO (5 mg/kg) and LDH + INDO $(10 \mathrm{mg} / \mathrm{kg})$ after intraperitoneal injections of LPS (LPS groups) and $0.9 \%$ saline solution (control groups). The bars represent the mean \pm standard deviation of body weight variation measured daily compared to control groups $* p<0.05, * * p<0.01, * * * p<0.001$, $* * * * p<0.0001$ by 2 -way in each day; compared to day $0{ }^{\#} p<0.05,{ }^{\#} p<0.01,{ }^{\# \#} p<0.001$, \#\#\# $\mathrm{p}<0.0001$; compared to day $1{ }^{\$} \mathrm{p}<0.05,{ }^{\$} \$ \mathrm{p}<0.01,{ }^{\$ \$} \$ \mathrm{p}<0.001,{ }^{\$ \$ \$} \mathrm{p}<0.0001$; compared

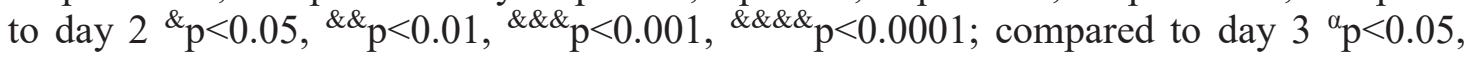
${ }^{\alpha \alpha} \mathrm{p}<0.01,{ }^{\alpha \alpha \alpha} \mathrm{p}<0.001,{ }^{\alpha \alpha \alpha \alpha} \mathrm{p}<0.0001$ between groups by ANOVA followed by Tukey posttest. 
Figure 9 Photomicrography of immunohistochemistry with anti-ibal antibody for microglia in the somatosensory cortex rats treated with indomethacin free or intercalated in model of neuroinflammation induced by LPS. Cresyl violet staining in the somatosensory cortex. (A-C) SAL + SAL, animals controls. (D-F) SAL + INDO, control animals treated with indomethacin. (G-I) SAL + LDH, control animals treated with LDHempty. (J-L) SAL + LDH-INDO, control animals treated with LDH-indomethacin. (M-O) LPS + SAL, animals injected with LPS and treated with saline solution; (P-R) treated with indomethacin (LPS + INDO); (S-U) treated with LDH-empty (LPS + LDH-empty) or (V$\mathrm{Y}$ ) treated with LDH-indomethacin (LPS + LDH-INDO). Arrows in O, U, R pointing microglia on stage activated and arrowheads in C, F, I, L, R, Y point to quiescent microglia. A, D, G, J, M, P, S, V: scale of $1000 \mu \mathrm{m}$. B, E, H, K, N, Q, T, X: $100 \mu \mathrm{m}$ scale. C, F, I, L, $\mathrm{O}, \mathrm{R}, \mathrm{U}, \mathrm{V}: 50 \mu \mathrm{m}$ scale.

Figure 10 Photomicrography of immunohistochemistry with anti-ibal antibody for microglia in the hippocampus rats treated with indomethacin free or intercalated in model of neuroinflammation induced by LPS. Cresyl violet staining in the somatosensory cortex. (A-C) SAL + SAL, animals controls. (D-F) SAL + INDO, control animals treated with indomethacin. (G-I) SAL + LDH, control animals treated with LDH-empty. (J-L) SAL + LDH-INDO, control animals treated with LDH-indomethacin. (M-O) LPS + SAL, animals injected with LPS and treated with saline solution; (P-R) treated with indomethacin (LPS + INDO); (S-U) treated with LDH-empty (LPS + LDH-empty) or (V-Y) treated with LDHindomethacin (LPS + LDH-INDO). Arrows in O, U, R pointing microglia on stage activated and arrowheads in C, F, I, L, R, Y point to quiescent microglia. A, D, G, J, M, P, S, V: scale of $1000 \mu \mathrm{m}$. B, E, H, K, N, Q, T, X: $100 \mu \mathrm{m}$ scale. C, F, I, L, O, R, U, V: 50 $\mu \mathrm{m}$ scale. 


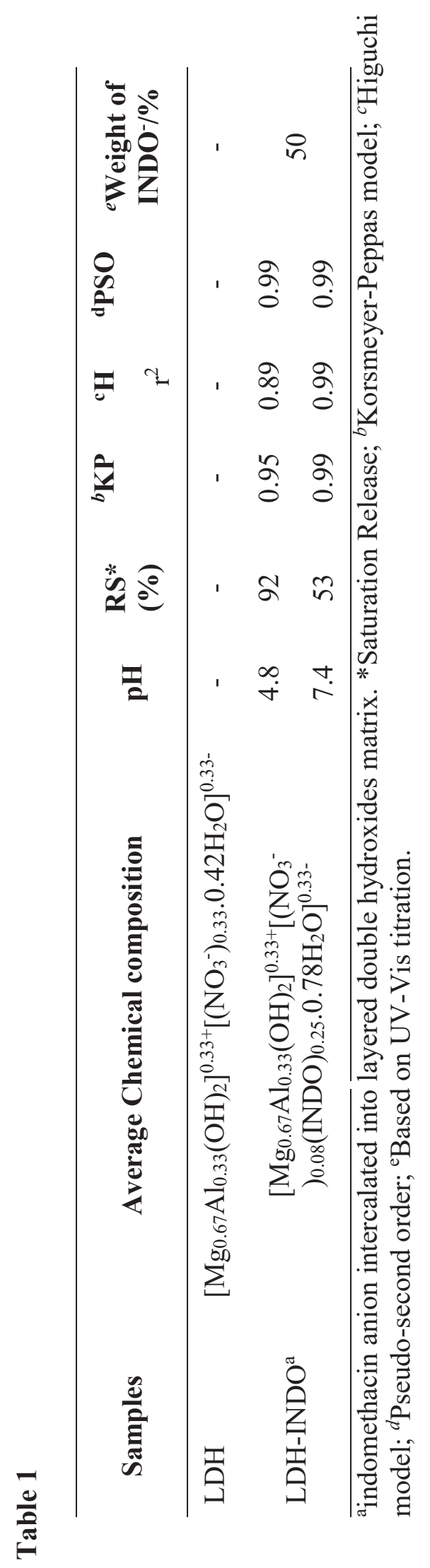


Table 2

\begin{tabular}{|c|c|c|c|}
\hline Groups & $\begin{array}{c}\text { Injectable } \\
\text { administration }\end{array}$ & $\begin{array}{c}\text { Administration by } \\
\text { gavage }\end{array}$ & $\begin{array}{c}\text { Number } \\
\text { of animals }\end{array}$ \\
\hline SAL+SAL ${ }^{a}$ (1) & $0.9 \%$ saline solution & $\begin{array}{l}0.9 \% \text { saline solution with } \\
7 \% \text { sodium bicarbonate }\end{array}$ & 7 \\
\hline SAL + INDO ${ }^{b}(2)$ & $0.9 \%$ saline solution & INDO $(5 \mathrm{mg} / \mathrm{kg})$ & 7 \\
\hline $\mathbf{S A L}+\mathbf{L D H}^{\mathbf{c}}(\mathbf{3})$ & $0.9 \%$ saline solution & LDH $(10 \mathrm{mg} / \mathrm{kg})$ & 7 \\
\hline SAL + LDH-INDO ${ }^{d}(4)$ & $0.9 \%$ saline solution & LDH-INDO $(10 \mathrm{mg} / \mathrm{kg})$ & 9 \\
\hline $\mathbf{L P S}^{\mathrm{e}}+\mathbf{S A L}(5)$ & LPS $(0.75 \mathrm{mg} / \mathrm{kg})$ & $\begin{array}{l}0.9 \% \text { saline solution with } \\
7 \% \text { sodium bicarbonate }\end{array}$ & 7 \\
\hline LPS + INDO (6) & LPS $(0.75 \mathrm{mg} / \mathrm{kg})$ & INDO $(5 \mathrm{mg} / \mathrm{kg})$ & 6 \\
\hline LPS + LDH (7) & LPS $(0.75 \mathrm{mg} / \mathrm{kg})$ & LDH $(10 \mathrm{mg} / \mathrm{kg})$ & 5 \\
\hline LPS+ LDH-INDO (8) & LPS $(0.75 \mathrm{mg} / \mathrm{kg})$ & LDH-INDO (10mg/kg) & 6 \\
\hline
\end{tabular}

${ }^{a}$ SAL: saline solution; ${ }^{b}$ INDO: indomethacin; ${ }^{c} \mathrm{LDH}$ : layered double hydroxides matrix; ${ }^{\mathrm{d}} \mathrm{LDH}-$ INDO: indomethacin anion intercalated into layered double hydroxides matrix in saline; ${ }^{~} \mathrm{LPS}$ : lipopolysaccharide. 


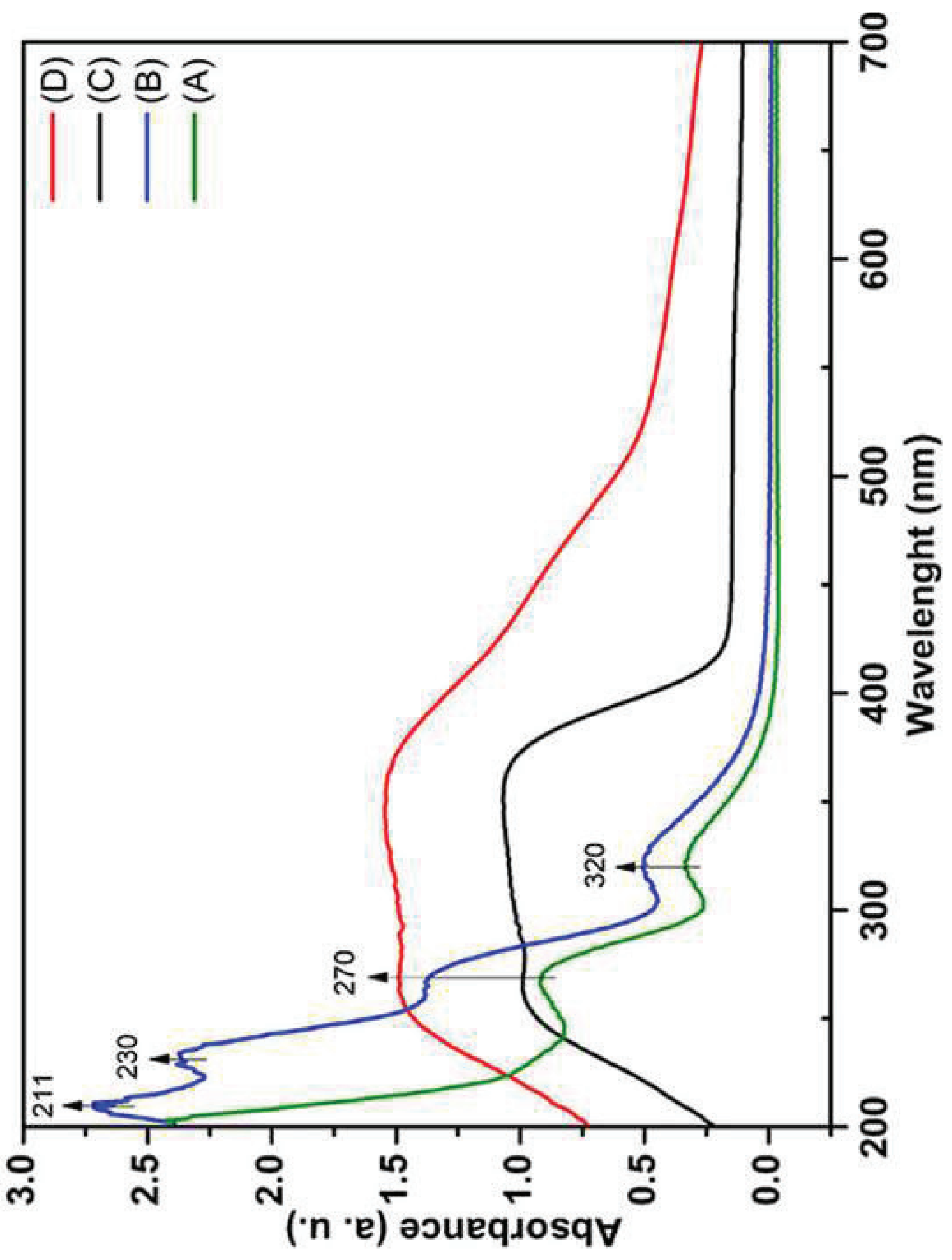




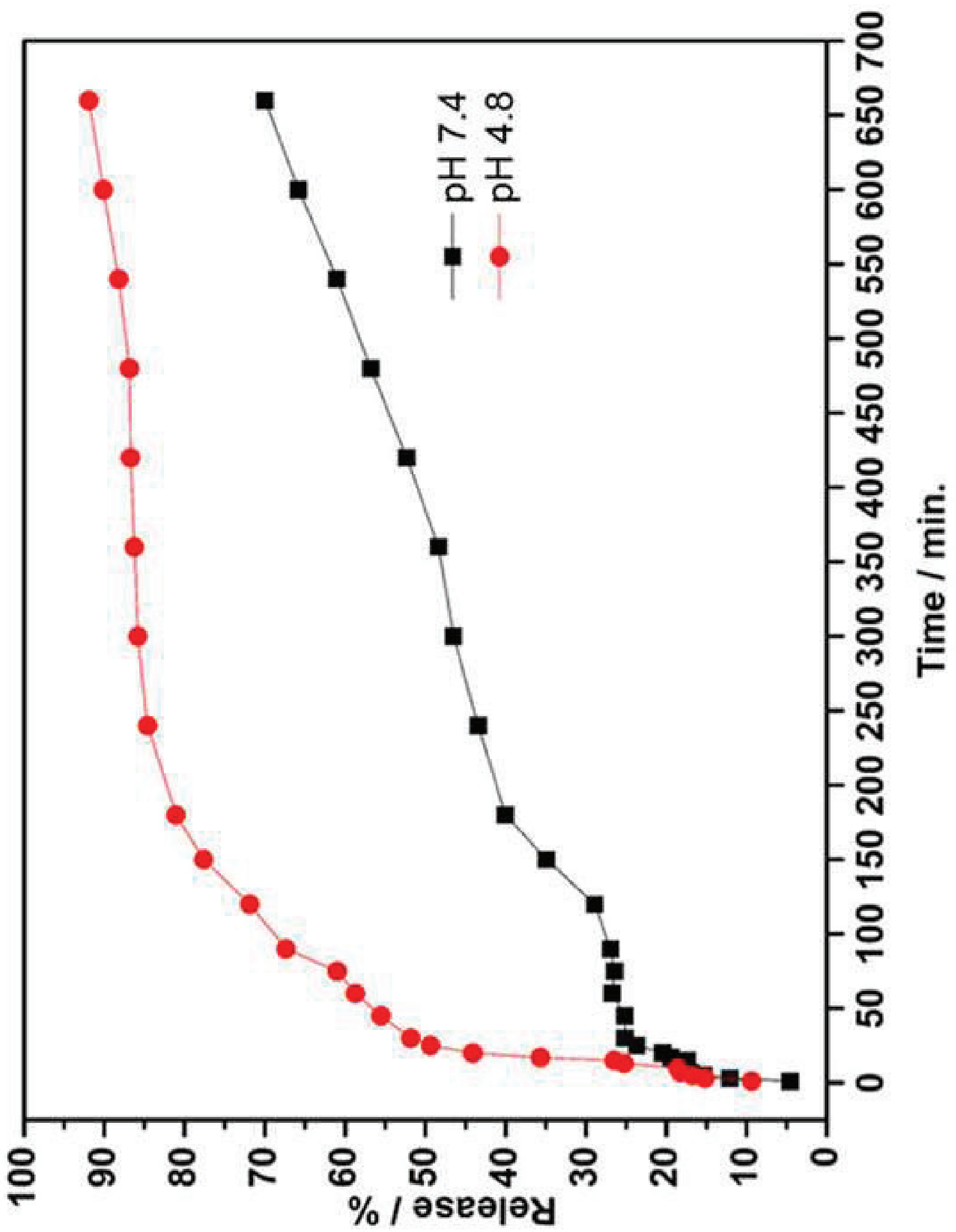



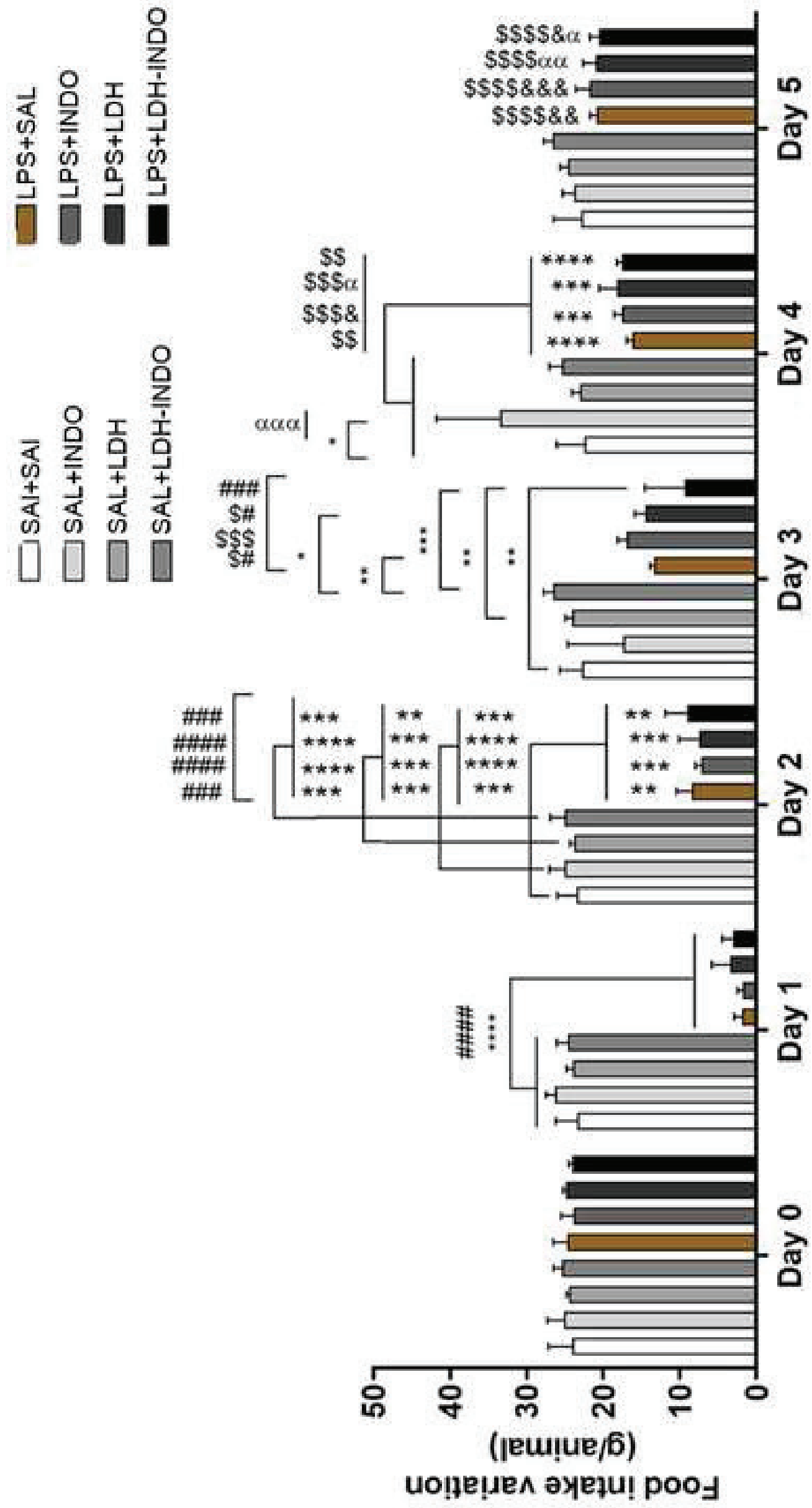


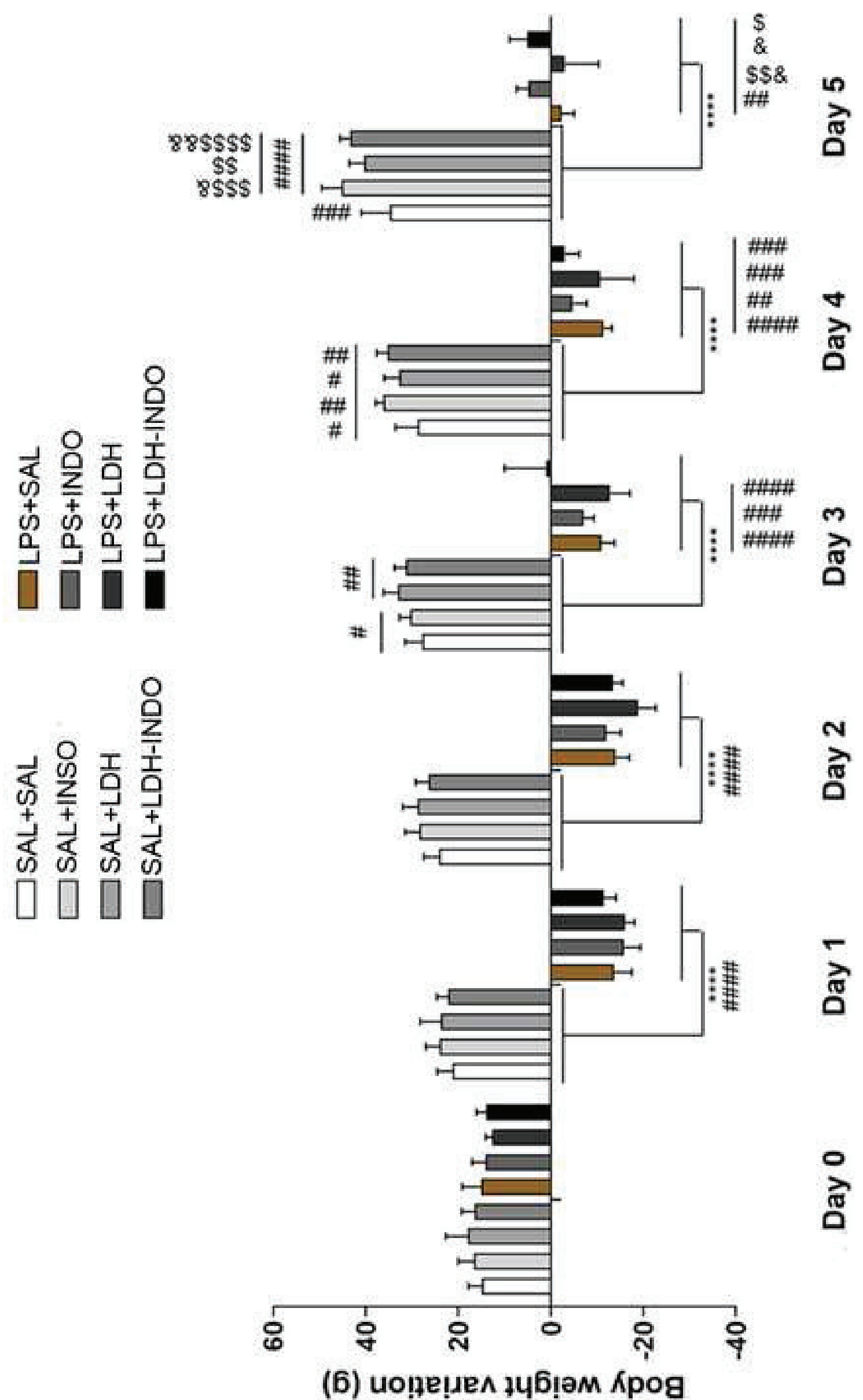




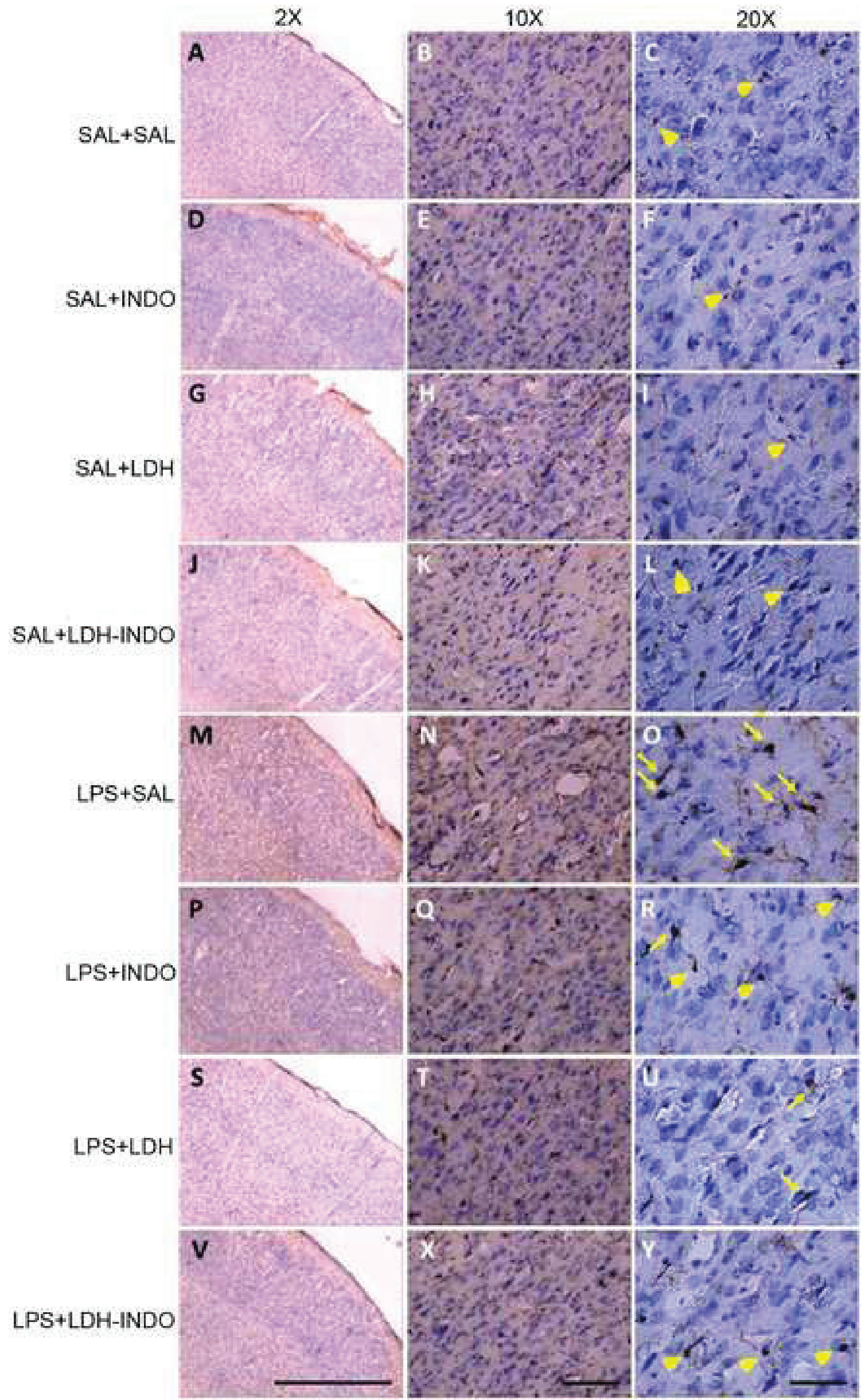




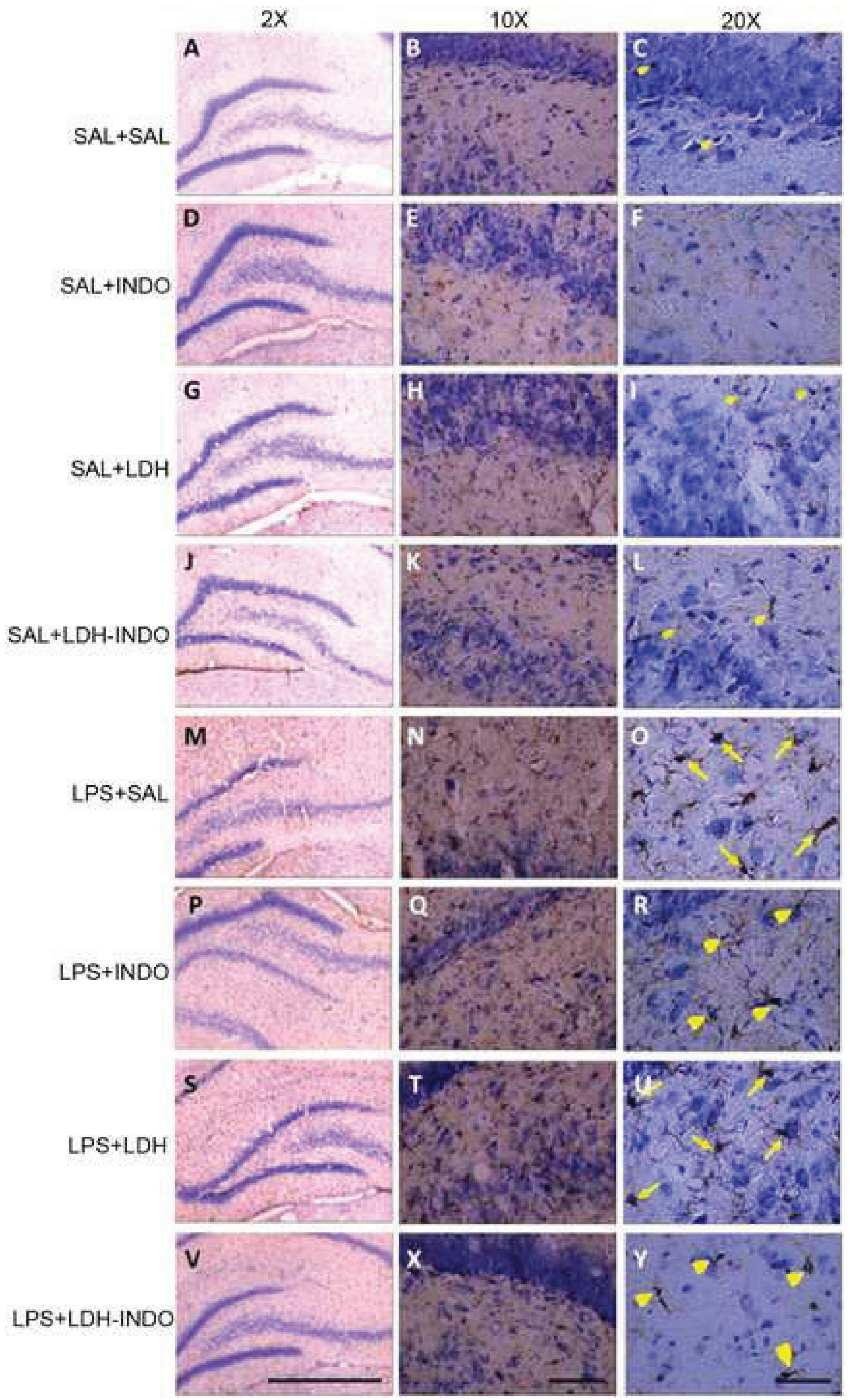




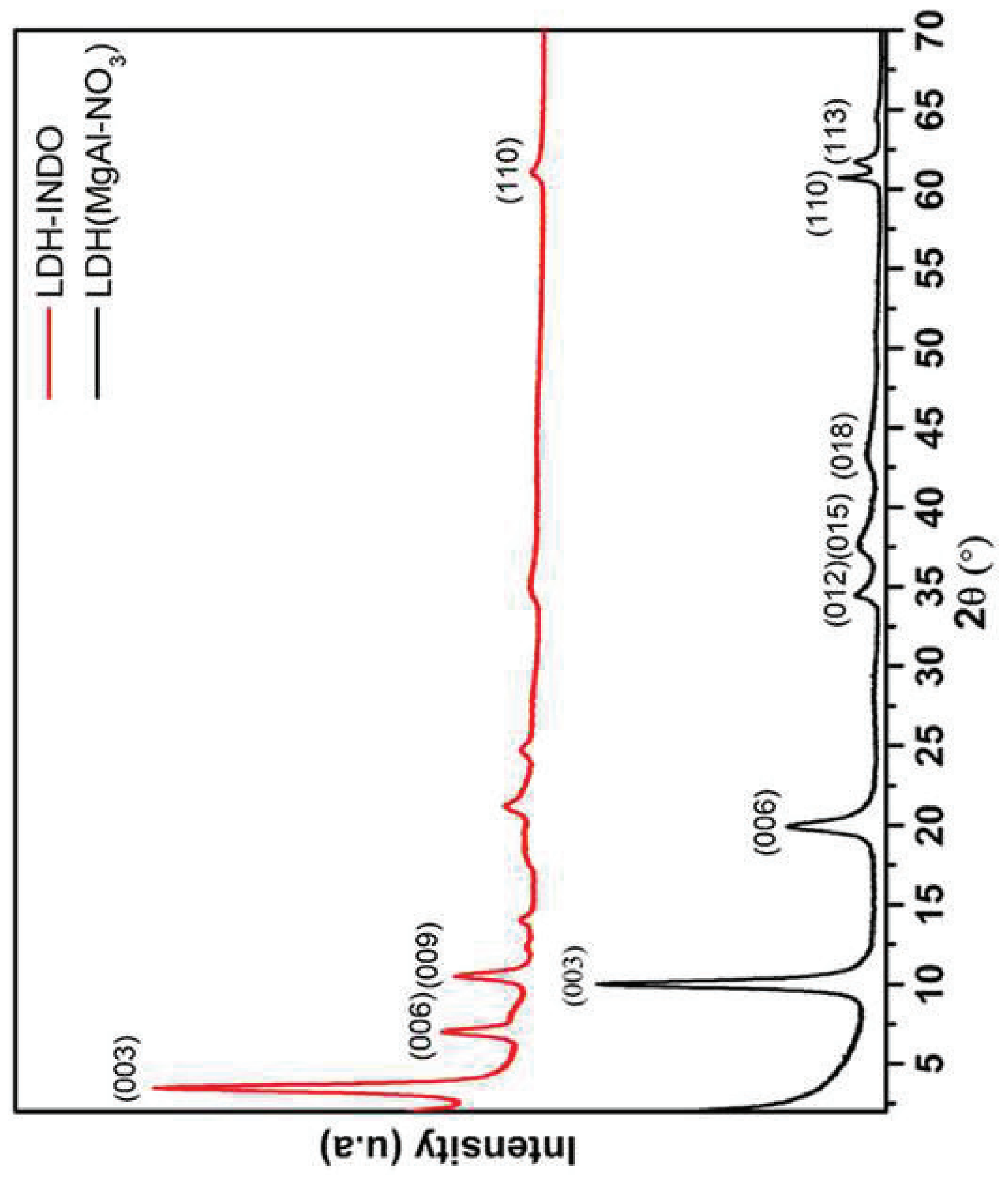




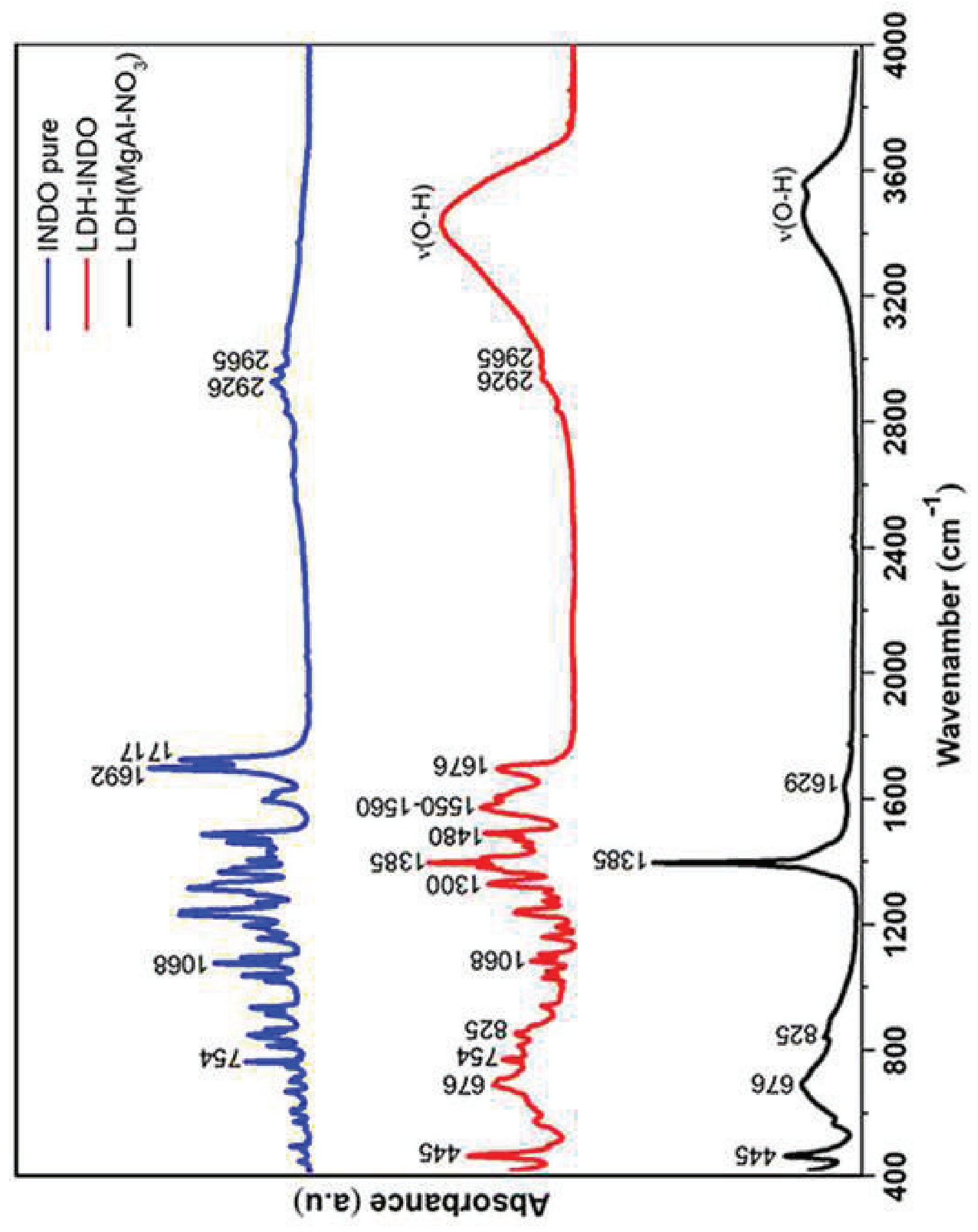



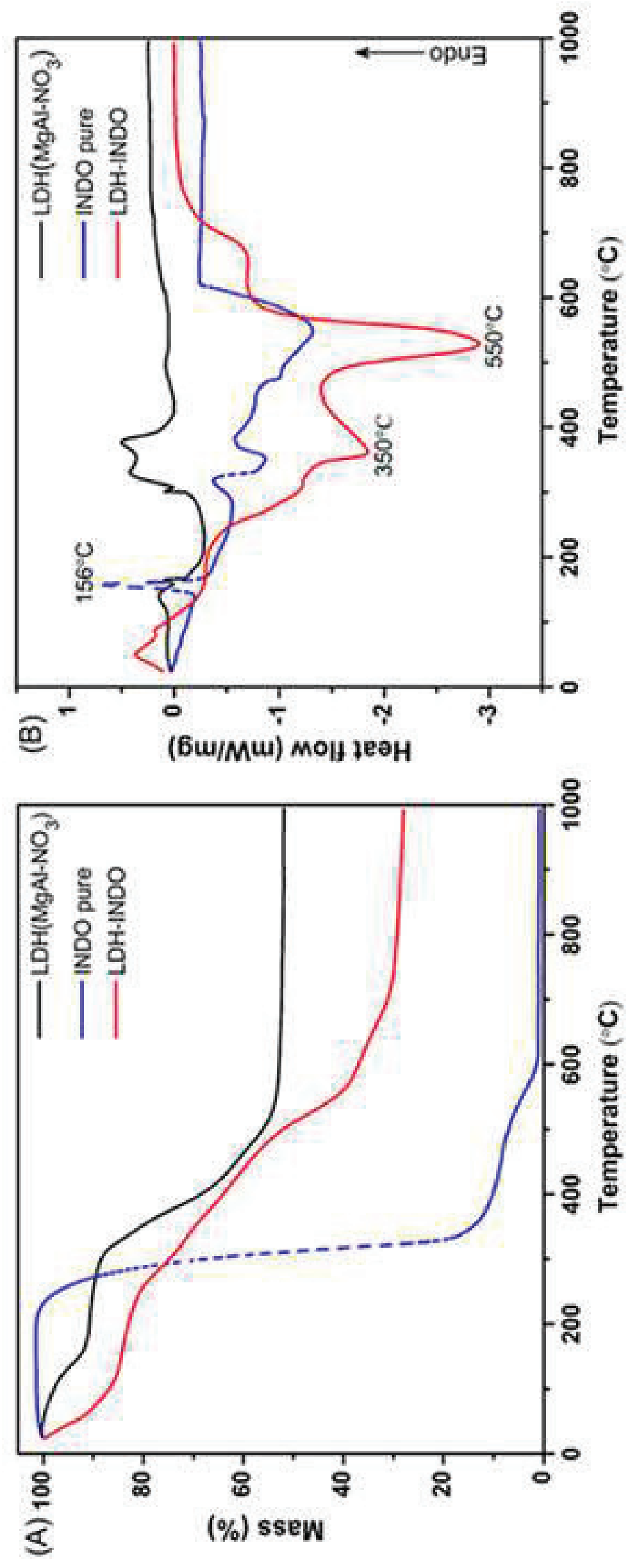

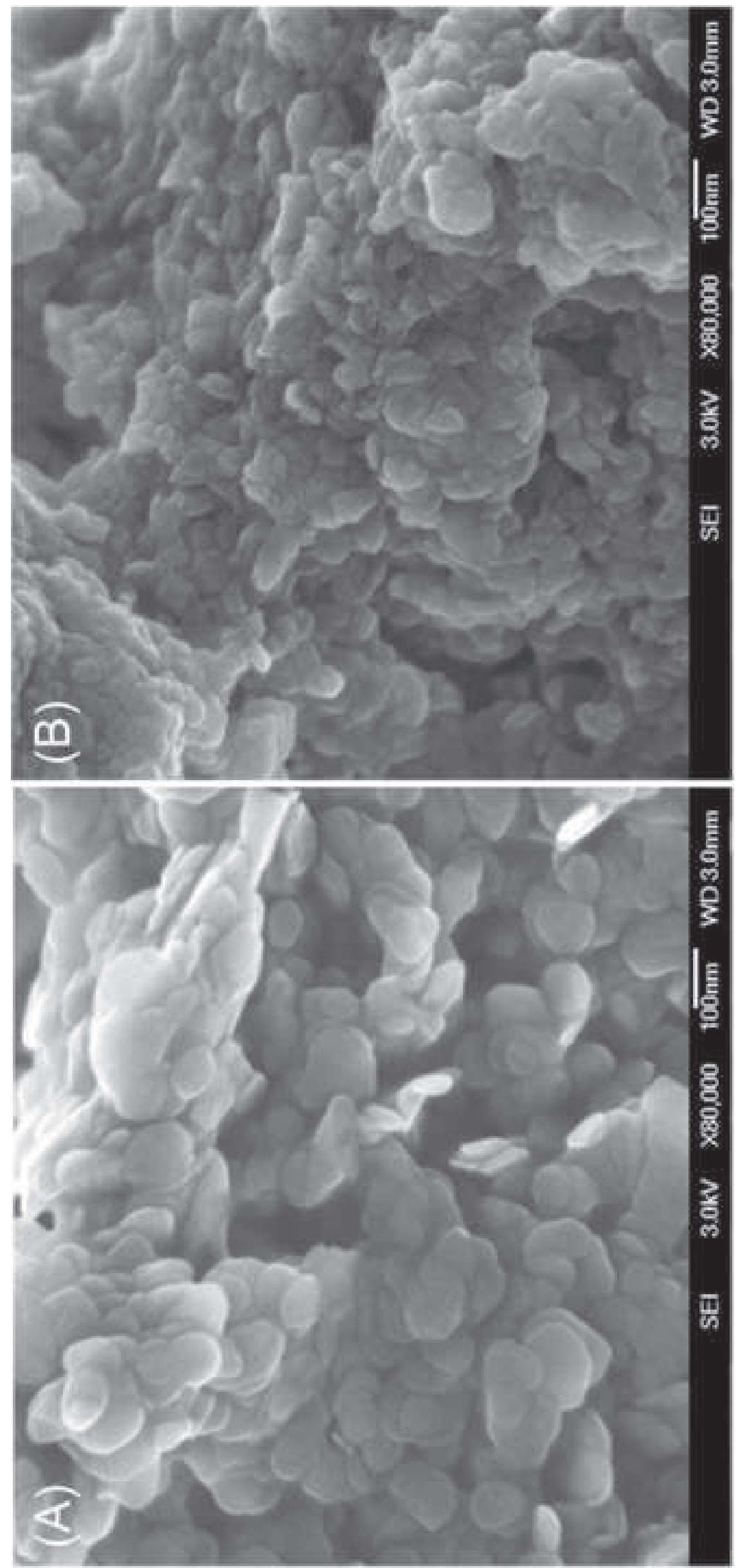